\title{
Investigation on Ti-6Al-4V Alloy Surface Characteristics Using Nano Grinding Wheel by Response Surface Methodology (RSM) with Artificial Neural Networking (ANN)
}

Deborah Serenade Stephen

SRM University

Sethuramalingam Prabhu ( $\sim$ prabhus@srmist.edu.in )

SRM University

Original Article

Keywords: 3\% nano Al203 grinding wheel, Surface roughness, Surface Temperature, Response Surface Methodology (RSM), Neural Network analysis, Analysis of Variance (ANOVA)

Posted Date: August 31st, 2020

DOI: https://doi.org/10.21203/rs.3.rs-66060/v1

License: (c) (1) This work is licensed under a Creative Commons Attribution 4.0 International License.

Read Full License 


\title{
Investigation on Ti-6Al-4V alloy surface characteristics using Nano grinding wheel by Response Surface Methodology (RSM) with Artificial Neural Networking (ANN)
}

\author{
Deborah Serenade Stephen ${ }^{1}$, Sethuramalingam Prabhu² \\ ${ }^{1}$ Assistant Professor, Department of Mechanical Engineering, SRM Institute of Science and \\ Technology, Chennai 603 203, India \\ ${ }^{2}$ Professor, Department of Mechanical Engineering, SRM Institute of Science and Technology, \\ Chennai 603 203, India \\ ${ }^{2}$ E-mail: prabhus@srmist.edu.in \\ ${ }^{2}$ Corresponding author
}

\section{Abstract}

In this research work, surface characteristics of Ti-6Al-4V alloy have been investigated and the grinding process has been optimized using nano grinding wheel. Experiments have been conducted using L27 full factorial design. Surface roughness prediction model in nano grinding wheel for Ti alloy was developed using Response Surface Methodology (RSM) and compared with the model using Artificial Neural Network (ANN) methodology to predict the experimental behavior of the system. Grinding wheels with and without $3 \%$ nano $\mathrm{Al}_{2} \mathrm{O}_{3}$ powders were fabricated and their surface characteristics like surface roughness, material removal rate (MRR) and temperature were measured. Grinding was carried out on grade 5 Ti alloy with different wheels by varying input parameters. On comparing experimental and predicted results, it was found that the empirical values of surface roughness were close to the predicted values by $5 \%$.

Keywords: $3 \%$ nano $\mathrm{Al}_{2} \mathrm{O}_{3}$ grinding wheel, Surface roughness, Surface Temperature, Response Surface Methodology (RSM), Neural Network analysis, Analysis of Variance (ANOVA)

\section{Introduction}

Machining of high hardness materials is one of the greatest challenges in the manufacturing sector. Surface finish at nano levels is an important requirement for grinding difficult-tomachine metals such as Titanium alloys. This alloy in its many grades, finds various industrial applications. It is widely used in aerospace and marine industry for its long life and corrosion resistance. This is of particular use in the medical field, to make highly precise surgical instruments, bone and dental implants - all of which require the excellent qualities of chemical inertness, corrosion resistance and long life. For many metals, grinding is used to obtain micro level surface finish and whenever there is a need to improve finish to sub-micro levels, lapping and super finishing processes or super-abrasives are used. To achieve these requirements, this work proposes use of $\mathrm{Al}_{2} \mathrm{O}_{3}$ grinding wheels with $3 \%$ nano $\mathrm{Al}_{2} \mathrm{O}_{3}$ powders, to withstand high temperature distribution, high cutting force absorption characteristics and obtain low wear rate of the given grinding wheel. A grinding wheel has been manufactured - evenly dispersed with $3 \%$ Nano- $\mathrm{Al}_{2} \mathrm{O}_{3}$ and the marking of this $3 \%$ nano grinding wheel is AA $100 \mathrm{~K} 5 \mathrm{~V} 8$.

\subsection{Previous work}

Hao Nan Li et al. [1] proposed textured grinding wheels that have active and passive areas on their grinding surface. It was found that texture-based wheels significantly improved surface finish and performance of grinding wheel due to minimization of wear of the wheel caused by 
factors like reduced work piece contact, grinding force and temperature of grinding zone. Ryszard Wojcik [2,3] tested different grinding wheel materials for grinding Ti alloys using minimum flow of cutting fluids in the heat affected zone and compared them with dry grinding. Since grinding $\mathrm{Ti}$ alloys requires high amount of cutting force and torque due to their hardenability, it is crucial for a proper cooling system to be in place. Surface roughness of the work pieces and deformation of grinding wheels were examined and it was found that flat surfaces were generated using minimum quantity lubrication. Wheel Li Xun, et al., [4] studied optimum surface burn threshold temperature in Ti alloy by grinding with cup-shaped wedges. Metallography of phase transformation of a cup shaped wheel was investigated and in order to increase efficiency of grinding, improve life of the wheel while reducing heat generation of $\mathrm{Ti}$ alloy, a self-cooling, cup-structured wheel was developed and this technique was compared with ordinary cooling techniques. The results showed that this self-inhaling, internal cooling resulted in $30 \%$ decrease in minimum grinding temperature and efficiency of wheel doubled, thereby improving the life of the wheel considerably.

You [5] used MWCNT directly as cutting grains in a nano structured grinding wheel. 1\% CNT was used to make the grinding wheel and tests showed that the best results of surface finish was obtained without functionalization of CNT. However, it was observed that varying the diameter of CNT influenced grinding effects. Prabhu, et al, [6] prepared SAE20W40 oil with CNT and used it as grinding fluid in machining D3 tool steel, which is a hard-to-machine metal. Taguchi L8 design of experiments was used and it was shown that surface finish of the mold and die material increased from micro to nano levels. AFM analysis was carried out on D3 tool steel, to check surface finish and see if micro cracks were present at nano levels. Chandrasekaran and Devarasiddappa [7] predicted a grinding model using neural network for LM25 metal matrix composite. Neural network model predicted an accuracy level of $94.2 \%$ and ANOVA test was used to find the most influential parameters for surface roughness. Surface plot and 2D graphs were plotted to study the combined effect of process parameters and results indicated that good surface finish was achieved by using a combination of high wheel velocity and low feed rate.

Davim.J.P, [8] in his book has showcased many machining experiments where Taguchi's design of experiments along with ANOVA, lead to quicker experimentation and better validation of results. Daria Sidorenko, et al., [9] used CNT with diamond cutting tools and investigated it both numerically and with experiments. Micro-mechanical studies were carried out on MWCNT material strengthening, which caused decrease in grain size of binders, which in turn improved hardness. Due to MWCNT reinforcement, a great improvement was possible in the diamond cutting wheel speeds. Dinesh Setti [10] et al. used minimum quantity lubrication technique to reduce environmental effect of coolants used during grinding process. Nano fluids were used as MQL, as they have superior lubrication characteristics and good heat dissipation properties. Nano fluids were used to grind $\mathrm{Ti}$ and the grinding forces reduced significantly even with low levels of nano particle concentration. However, higher concentrations of the nano particles yielded better surface finish. Salman Pervaiz et al., [11] catalogued challenges in difficult-tomachine materials like Titanium alloys. He highlighted difficulties imposed on surface integrity like residual stresses, work hardening, micro structural alterations, cracking and white layer formation. He re-iterated that selection of cutting tool was always difficult for these materials. Hybrid machining was used to machine difficult-to-machine metals using metal-bonded diamond grinding wheel [12].

Suleyman Neseli et al., [13] proposed the combined use of Taguchi and Response Surface Methodology (RSM) in external cylindrical grinding. Single objective optimization technique was used to minimize surface roughness and vibration of wheel. The model developed to 
determine optimal operating parameters showed that a hybrid approach was essential for the success of a robust process. Chaojie Liu [14] mentioned that high temperature on grinding leads to work piece damage, micro cracks, tool wear and quality. Back propagation neural network was used to predict high speed grinding temperature of titanium matrix composites. Deng et al., [15] proposed a hybrid artificial neural network (ANN) model to optimize process parameters of machining. A back propagation neural network model was adopted to improve the accuracy of the model and results obtained with NC camshaft grinding showed that the hybrid model was the best method to optimize process parameters.

In the present work, grinding wheels with and without $3 \%$ nano $\mathrm{Al}_{2} \mathrm{O}_{3}$ powders were fabricated and their surface characteristics like surface roughness, MRR and temperature were measured. Grinding was carried out on $\mathrm{Ti}$ alloy with both wheels while experiments were designed with L27 full factorial design to vary input parameters. Surface roughness prediction model to grind Ti alloy using 3\% nano grinding wheel was developed using Artificial Neural Network (ANN) and Response Surface Methodology (RSM) methodologies in order to predict the behavior of the system. Experiments were then carried out to confirm them.

\section{Experimental setup}

The experimental setup consists of a grinding wheel mounted on the horizontal spindle of the surface grinding machine. As shown in Figure 1, the surface grinding machine consists of a table that can move on two axes and a mechanical vice mounted on it to hold test pieces in place. Figure 2 shows the grinding wheel incorporated with $3 \%$ nano $\mathrm{Al}_{2} \mathrm{O}_{3}$ powder and their properties are tabulated in Table 2. Figure 3 shows Ti-6Al- 4V pieces of dimensions 22 x 25 x $27 \mathrm{~mm}$ after being EDM wire cut from a bought Ti block. Four surfaces of all these test pieces were used for experimentation and L27 optimization technique was employed to determine Material Removal Rate (MRR) and surface Roughness $\left(R_{a}\right)$. The input parameters used were varied in 3 levels as shown in Table 1.

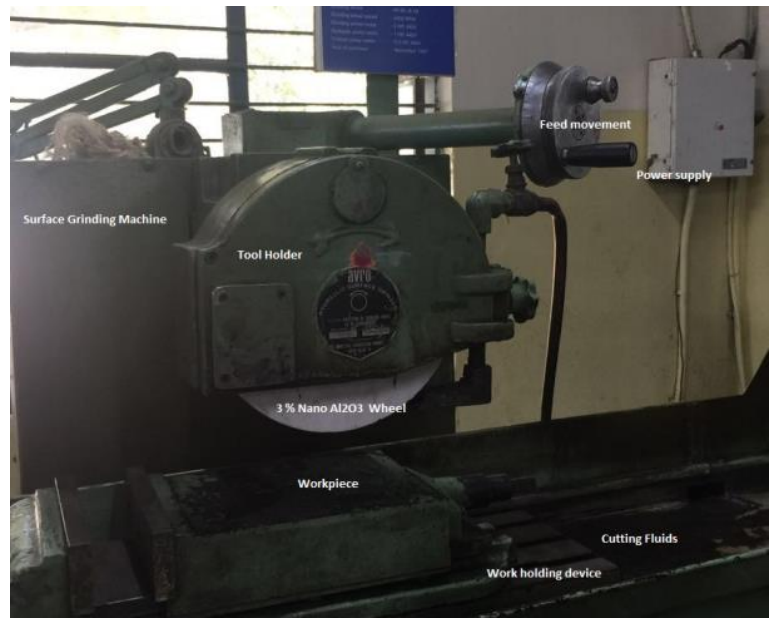

Figure 1. Surface Grinding Machine

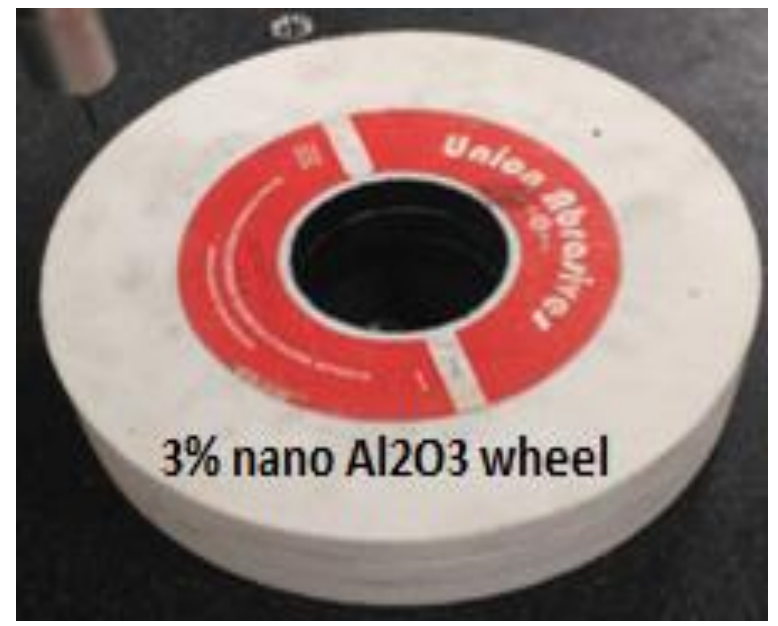

Figure 2. Nano Grinding wheel

Table1 : Machining parameter levels

\begin{tabular}{lcccc}
\hline Parameters & Symbol & Level 1 & Level 2 & Level 3 \\
\hline Cutting speed (rpm) & $\mathrm{S}$ & 2500 & 2800 & 3100 \\
Feed (mm/min) & $\mathrm{F}$ & 0.1 & 0.2 & 0.3
\end{tabular}


Table.2 Properties of the $3 \%$ nanoAl $\mathrm{O}_{2} \mathrm{O}_{3}$ grinding wheel

\begin{tabular}{lc}
\hline Specifications & Description \\
\hline Nano-Al2O3 powder Particle size & $<50 \mathrm{~nm}$ \\
Surface area & $>40 \mathrm{~m}^{2} / \mathrm{g}$ \\
Melting point & $2313 \mathrm{~K}$ \\
Dimensions of wheel & $250 \times 20 \times 76.2 \mathrm{~mm}$ \\
Bond Type & Vitrified Bond \\
Wheel type & AA100K5V8 \\
abrasive is aluminum oxide & $\mathrm{AA}$ \\
Average grit size in inch mesh & 100 \\
Hardness of the wheel & $\mathrm{K}$ \\
Porosity of the wheel & 5 \\
Vitrified bond & $\mathrm{V}$ \\
\hline
\end{tabular}

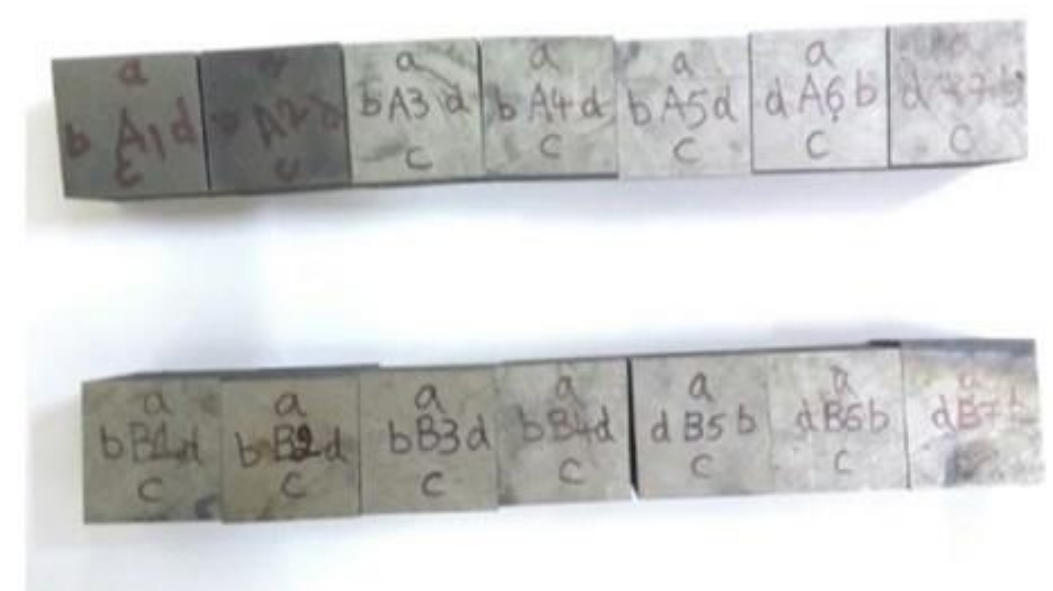

Figure 3 Ti-6Al-4V work pieces

The hardness of the wheel $(\mathrm{K})$, represented as the quantity of force required to fracture a single abrasive grit. The hardness measurements were carried out for both grinding wheels in hardness tester RAB250. A 1/16 inch diameter ball indenter was used to create an impression while applying a $100 \mathrm{~kg}$ load to obtain the hardness of the grinding wheel. Hardness values for abrasive wheel and $3 \%$ nano $\mathrm{Al}_{2} \mathrm{O}_{3}$ Grinding wheel were $54 \mathrm{HRC}$ and $70 \mathrm{HRC}$ respectively. Increase in hardness of the nano grinding wheel was $22.8 \%$ more than the abrasive wheel and this was due to the large surface-to-volume ration of nano materials that filled voids in the wheel structure. Hardness also improved life of the wheel along with low heat transfer effects.

\section{Results and Discussions}

\subsection{Circularity analysis of $3 \% \mathrm{Al}_{2} \mathrm{O}_{3}$ nano Grinding wheel}


The grinding wheels were subjected to circularity tests to determine their dimensions and to detect any defect in the circularity of the wheel as this is essential for the surface quality of the test piece. This test was carried out using ZEISS Contura G2 Coordinate Measuring Machine (CMM), which is a device capable of measuring physical geometrical characteristics of most objects. This machine can be either manually controlled by an operator or computer controlled. A ruby probe attached to a moving axis enables these measurements. Figure 4 depicts the circularity test results for the wheels using CMM software with a magnification of $100 \mu \mathrm{m}$.

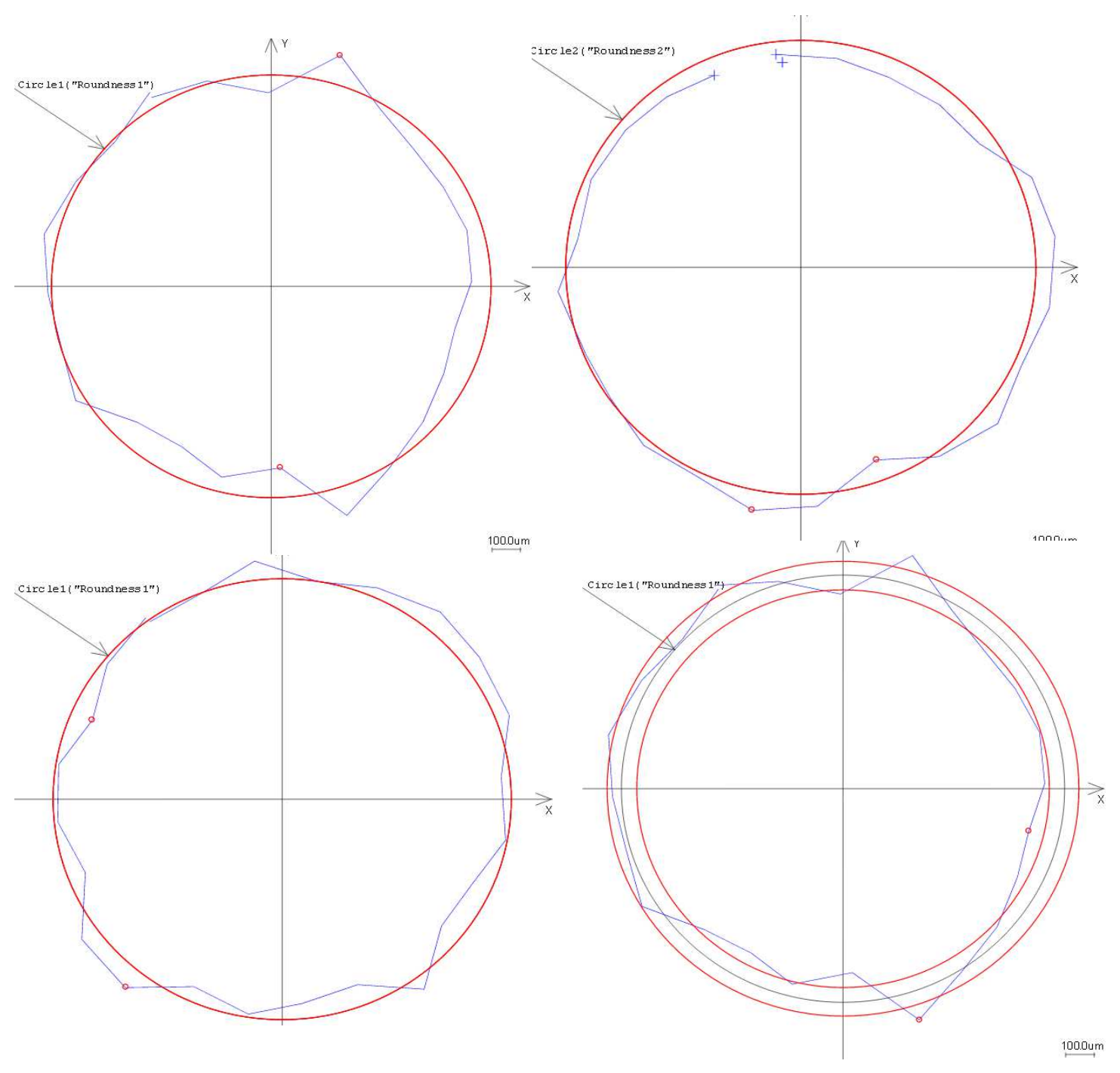

Figure 4 Circularity error of grinding wheel for a) Ordinary Grinding wheel before Grinding, $0.2128 \mu \mathrm{m}, \mathrm{b}$ ) Ordinary Grinding wheel after Grinding $0.1369 \mu \mathrm{m}$ c) $3 \% \mathrm{Nano}^{\mathrm{Al}} \mathrm{O}_{3} \mathrm{Grinding}$ wheel before Grinding $0.2093 \mu \mathrm{m}$ d) $3 \%$ Nano $\mathrm{Al}_{2} \mathrm{O}_{3}$ Grinding wheel after Grinding $0.098 \mu \mathrm{m}$.

The roundness values of $3 \% \mathrm{Al}_{2} \mathrm{O}_{3}$ nano grinding wheel and normal $\mathrm{Al}_{2} \mathrm{O}_{3}$ are $0.098 \mu$ and $0.1369 \mu$ respectively. There is also a good improvement in the geometrical shape and 
circularity form of the nano grinding wheel. When compared with the ordinary wheel, $3 \% \mathrm{Al}_{2}$ $\mathrm{O}_{3}$ nano grinding wheels shows $28.4 \%$ improvement in circularity. This is due to nano size $\mathrm{Al}_{2} \mathrm{O}_{3}$ particles, which filled and impregnated the pores in the grinding wheel. These nanoparticles absorb forces, lower temperature by distribution and maintains uniform bonding between particles with less pore sizes.

\subsection{Effect of vibration analysis on the $3 \%$ Nano $\mathrm{Al}_{2} \mathrm{O}_{3}$ Grinding wheel}

Both the $3 \%$ Nano $\mathrm{Al}_{2} \mathrm{O}_{3}$ grinding wheel and the ordinary $\mathrm{Al}_{2} \mathrm{O}_{3}$ grinding wheel were subjected to free vibrations test and the damping factor of the two wheels were found out. The experimental setup was as portrayed in Figure 5. The two wheels were firmly hung with the help of a thin rope and were subjected to vibration, by hitting them with a metal rod an appropriate number of times. An accelerometer was attached to the wheels with the help of wax, which sent the output in the form of various graphs, which were automatically plotted in the system. The amplitude versus frequency graph was also plotted and this helped find the damping factor.
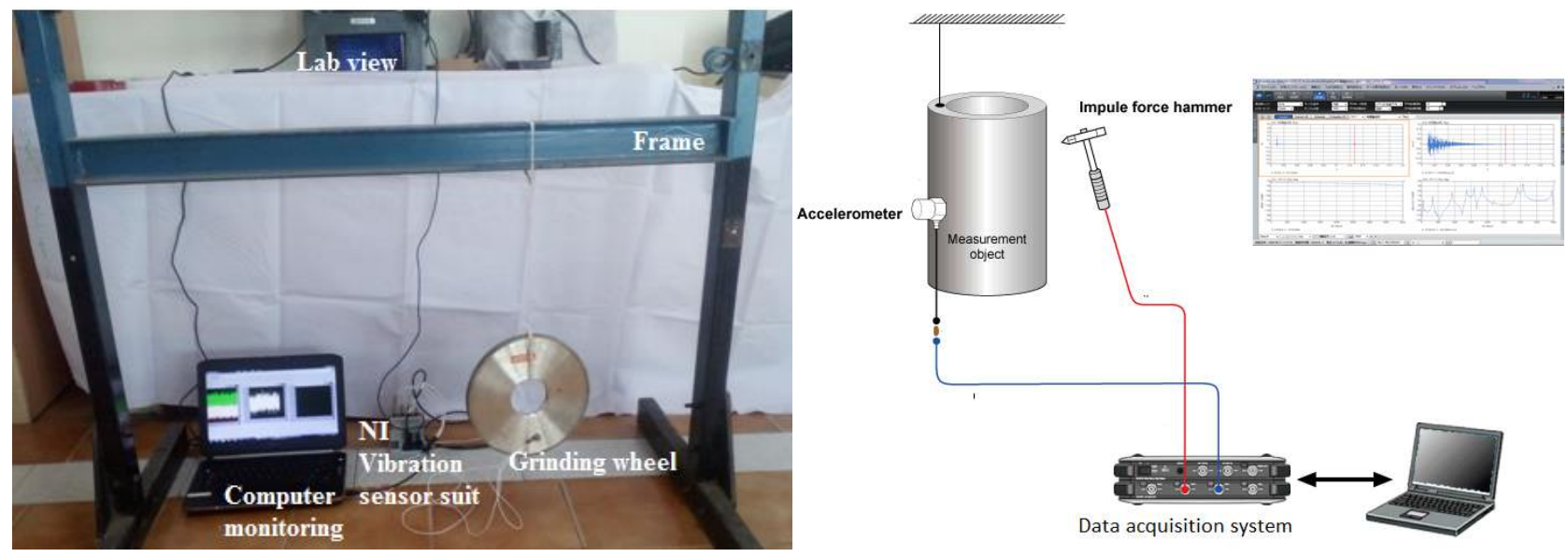

Figure 5 Experimental vibration analysis of the $3 \%$ Nano $\mathrm{Al}_{2} \mathrm{O}_{3}$ grinding wheel (left) and NI cDAQ setup with lab view analysis (Right)

NI lab view 2015, along with hardware of impulse force hammer of range of 0-500 N, was used to determine amplitude versus frequency graphs. Accelerometer with a sensitivity of $2.5 \mathrm{mV} / \mathrm{g}$ and vibration data acquisition system, NI9234 with 16 channel chassis were used. The damping factor of the ordinary $\mathrm{Al}_{2} \mathrm{O}_{3}$ grinding wheel was found to be 0.6042 and the damping factor of $3 \%$ Nano $\mathrm{Al}_{2} \mathrm{O}_{3}$ grinding wheel was found to be 0.9049 , which was greater than the damping factor of ordinary $\mathrm{Al}_{2} \mathrm{O}_{3}$ grinding wheel. The frequency first obtained from the ordinary $\mathrm{Al}_{2} \mathrm{O}_{3}$ grinding wheel was $220 \mathrm{~Hz}$ and that of $3 \%$ nano $\mathrm{Al}_{2} \mathrm{O}_{3}$ grinding wheel was found to be $175 \mathrm{~Hz}$.

\subsection{Response Surface Methodology (RSM)}

This was adopted with L27 orthogonal array of experiments to optimize grinding process for wheels with and without $3 \% \mathrm{Al}_{2} \mathrm{O}_{3}$ nano powder. This model was useful as an approximation model for finding response surface for the most influential parameter. The response surface model coefficients were estimated from the experimental results using Minitab 16. Eqn. (1) was 
generated from this software according to input variables in coded form and interaction terms with surface roughness (y) were given as follows.

$y=a_{0}+a_{1} x_{1}+a_{2} x_{2}+a_{3} x_{3}+a_{11} x_{1}^{2}+a_{22} x_{2}^{2}+a_{33} x_{3}^{2}+a_{12} x_{1} x_{2}+a_{13} x_{1} x_{3}+$ $a_{23} x_{2} x_{3}$

The coefficient ao represents the coefficient, $\mathrm{a}_{\mathrm{i}}$, linear variables, $\mathrm{a}_{\mathrm{ii}}$, quadratic variable findings, and the coefficients $\mathrm{a}_{\mathrm{ij}}$ are the interaction variable effects. With experimentation, the full form of the derived mathematical models for surface roughness for both grinding wheels, with and without $3 \%$ nano $\mathrm{Al}_{2} \mathrm{O}_{3}$ powder are shown in equations 2 and 3 as follows.

Ra with Ordinary Grinding wheel $(y 1)=1.46-0.00107 x_{1}+2.38 x_{2}-1.5 x_{3}+$ $0.06 x_{2}^{2}-55 x_{3}^{2}-0.000840 x_{1} x_{2}+0.00092 x_{1} x_{3}$

$\mathrm{Ra}$ with Nano $\mathrm{Al}_{2} \mathrm{O}_{3}$ Grinding wheel $(y 2)=-1.19+0.00103 x_{1}+0.65 x_{2}-13.6 x_{3}-$ $2.91 x_{2}^{2}-136 x_{3}^{2}+0.000191 x_{1} x_{2}+0.00577 x_{1} x_{3}$

The analysis of variance (ANOVA) was used to investigate which parameter had the most influence on surface roughness. In the ANOVA test, the total variance was split into different sections - a term related to each factor level and a term related to errors. The ANOVA table for a quadratic model of response surface, for the ordinary grinding wheel and the $3 \%$ nano $\mathrm{Al}_{2} \mathrm{O}_{3}$ grinding wheel are depicted in Table 3. The general linear ANOVA model consists of different input parameters, errors, interaction terms, residual values, sum of squares, F-test and P-test values. The $\mathrm{P}$ - test denotes the significance of process. In this test, a value less than 0.05 indicated the presence of a significant parameter. Higher F-test values denoted greater importance of that parameter. For quadratic Response Surface model (RSM) of the nano grinding wheel, cutting speed and depth of cut were both statistically significant as p-values were less than 0.05. The square terms for cutting speed and feed were also found to be significant. However, the significant interactive terms were cutting speed and depth of cut. The F-value test showed that feed was the most significant factor. The highest percentage of contribution was exerted by the square of feed term. Likewise, the quadratic model for 3\% Nano grinding wheel yielded similar significance of squares for cutting speed and errors were reduced significantly when compared to the ordinary wheel model.

Table 3 ANOVA table for surface response for both wheels (response: Surface roughness for ordinary grinding wheel and $3 \% \mathrm{Al}_{2} \mathrm{O}_{3}$ nano grinding wheel) 


\begin{tabular}{|c|c|c|c|c|c|c|c|c|c|c|c|}
\hline Source & $\begin{array}{l}\text { D } \\
\text { F }\end{array}$ & $\begin{array}{c}\text { Seq } \\
\dot{\text { SS }}\end{array}$ & $\begin{array}{c}\% \\
\text { Cont } \\
\text { ribu } \\
\text { tion }\end{array}$ & $\begin{array}{c}\text { F- } \\
\text { va } \\
\text { lu } \\
\text { e }\end{array}$ & $\begin{array}{l}\text { P- } \\
\text { Va } \\
\text { lue }\end{array}$ & $\begin{array}{c}\text { Remar } \\
\text { ks }\end{array}$ & $\begin{array}{c}\text { Seq. } \\
\text { SS }\end{array}$ & $\begin{array}{c}\% \\
\text { Cont } \\
\text { ribut } \\
\text { ion }\end{array}$ & $\begin{array}{l}\text { F- } \\
\text { val } \\
\text { ue }\end{array}$ & $\begin{array}{l}\text { P- } \\
\text { Va } \\
\text { lue }\end{array}$ & $\begin{array}{c}\text { Remark } \\
\text { S }\end{array}$ \\
\hline $\begin{array}{l}\text { Regression } \\
\text { Model }\end{array}$ & 8 & 0.011 & 25.33 & $\begin{array}{c}0.7 \\
6\end{array}$ & 0.63 & $\begin{array}{c}\text { Not } \\
\text { Significant }\end{array}$ & 0.0339 & 53.0 & 2.54 & 0.04 & Significant \\
\hline $\begin{array}{l}\text { Cutting } \\
\text { speed (rpm) } \\
\mathrm{X}_{1}\end{array}$ & 1 & 0.001 & 3.79 & $\begin{array}{c}0.9 \\
*\end{array}$ & $\begin{array}{c}0.03 \\
*\end{array}$ & Significant & 0.0016 & 2.54 & 0.97 & $\begin{array}{c}0.03 \\
*\end{array}$ & Significant \\
\hline $\begin{array}{l}\text { Feed } \\
(\mathrm{mm} / \mathrm{min}) \\
\mathrm{X}_{2}\end{array}$ & 1 & 0.001 & 4.26 & $\begin{array}{c}1.0 \\
*\end{array}$ & 0.3 & $\begin{array}{c}\text { Not } \\
\text { Significant }\end{array}$ & 0.0001 & 0.229 & 0.09 & 0.77 & $\begin{array}{c}\text { Not } \\
\text { Significant }\end{array}$ \\
\hline $\begin{array}{l}\text { Depth of } \\
\text { cut(mm) } \\
\mathrm{X}_{3}\end{array}$ & 1 & $\begin{array}{c}0.000 \\
012\end{array}$ & 0.025 & $\begin{array}{c}0.0 \\
1\end{array}$ & 0.93 & $\begin{array}{c}\text { Not } \\
\text { Significant }\end{array}$ & 0.0009 & 1.48 & 0.57 & 0.4 & $\begin{array}{c}\text { Not } \\
\text { Significant }\end{array}$ \\
\hline $\mathrm{X}_{1}^{2}$ & 1 & 0.002 & 5.47 & $\begin{array}{c}1.3 \\
*\end{array}$ & $\begin{array}{c}0.06 \\
*\end{array}$ & Significant & 0.0019 & 3.05 & 1.17 & $\begin{array}{c}0.02 \\
*\end{array}$ & Significant \\
\hline $\mathrm{X}_{2}^{2}$ & 1 & $\begin{array}{c}0.000 \\
001\end{array}$ & 0.002 & $\begin{array}{c}0.0 \\
0\end{array}$ & 0.97 & $\begin{array}{c}\text { Not } \\
\text { Significant }\end{array}$ & 0.0038 & 5.93 & $2.27 *$ & $\begin{array}{c}0.01 \\
*\end{array}$ & Significant \\
\hline $\mathrm{X}_{3}^{2}$ & 1 & $\begin{array}{c}0.000 \\
138\end{array}$ & 0.30 & $\begin{array}{c}0.0 \\
7\end{array}$ & 0.79 & $\begin{array}{c}\text { Not } \\
\text { Significant }\end{array}$ & 0.0008 & 1.29 & 0.50 & 0.49 & $\begin{array}{c}\text { Not } \\
\text { Significant }\end{array}$ \\
\hline $\mathrm{X}_{1} * \mathrm{X}_{2}$ & 1 & $\begin{array}{c}0.002 \\
855\end{array}$ & 6.16 & $\begin{array}{c}1.4 \\
*\end{array}$ & 0.23 & $\begin{array}{c}\text { Not } \\
\text { Significant }\end{array}$ & 0.0001 & 0.229 & 0.09 & 0.77 & $\begin{array}{c}\text { Not } \\
\text { Significant }\end{array}$ \\
\hline $\mathrm{X}_{1} * \mathrm{X}_{3}$ & 1 & $\begin{array}{c}0.000 \\
034\end{array}$ & 0.07 & $\begin{array}{c}0.0 \\
2\end{array}$ & 0.89 & $\begin{array}{c}\text { Not } \\
\text { Significant }\end{array}$ & 0.0013 & 2.10 & 0.81 & 0.3 & $\begin{array}{c}\text { Not } \\
\text { Significant }\end{array}$ \\
\hline Error & 18 & $\begin{array}{c}0.014 \\
578\end{array}$ & 30.26 & & & & 0.0101 & 15.6 & & & \\
\hline Total & 26 & $\begin{array}{c}0.046 \\
313 \\
\end{array}$ & & & & & 0.0640 & & & & \\
\hline & & R-sq & $\begin{array}{c}75.3 \\
\%\end{array}$ & & & & & R-sq & $83 \%$ & & \\
\hline & & $\begin{array}{c}\text { R- } \\
\text { sq(ad } \\
\text { j) }\end{array}$ & $69 \%$ & & \multicolumn{2}{|c|}{ *Significant } & & $\begin{array}{c}\text { R- } \\
\text { sq(adj) }\end{array}$ & $75 \%$ & & \\
\hline
\end{tabular}

The developed RSM models for surface finish of Ti alloy using both ordinary and $3 \% \mathrm{Al}_{2} \mathrm{O}_{3}$ nano grinding wheels were analysed using residual plots. The residual plots for response parameters of both wheels were shown in Figure 6 (i-iv). The predicted residual values were compared with real experimental grinding values and data were fitted approximately in a straight line. A minimal error was seen, which showed good correlation between the two different techniques as portrayed in Figure 6 (i). Figure 6 (ii) depicts residual error with calculated values and their spread in both positive and negative directions, depict equal error dispersion for both nano grinding wheels. The statistics of residuals are denoted by the histogram in Figure 6(iii) and Figure 6(iv) depicts the residuals calculated for grinding experiments. It was clearly identified that correlation exists in both directions uniformly for all parameters. On the whole, analysis of residual plots for the $3 \% \mathrm{Al}_{2} \mathrm{O}_{3}$ nano wheel responses, show that the model is adequate for the system. 


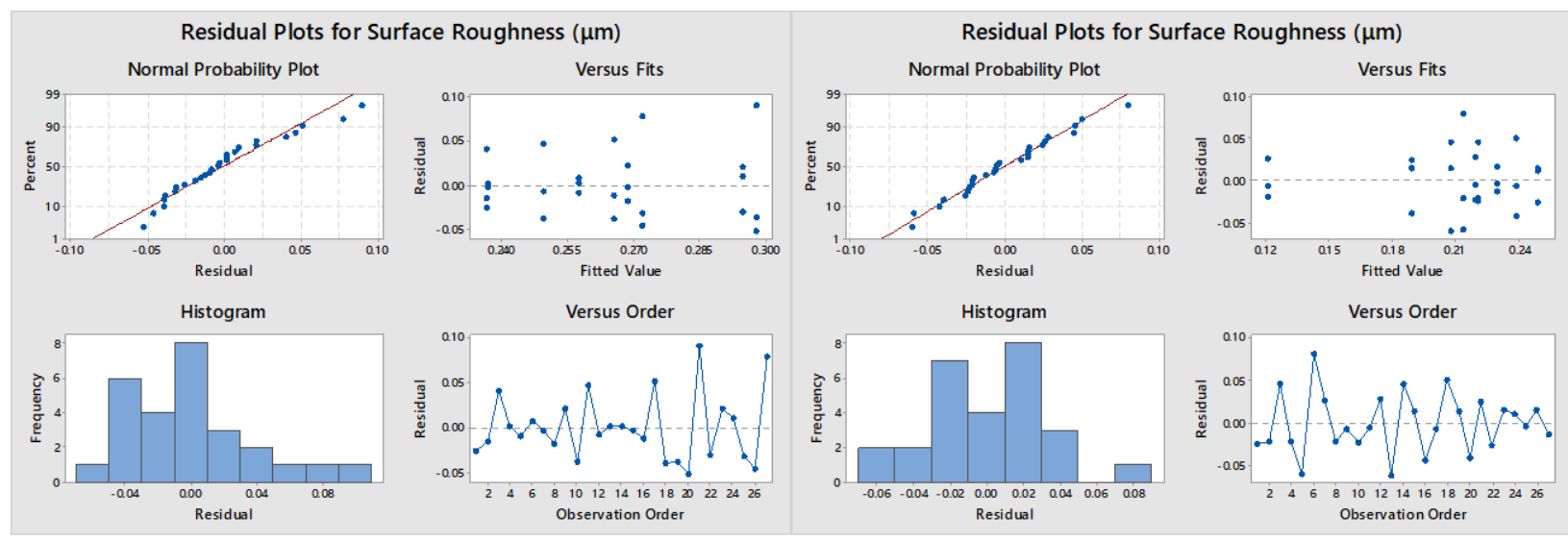

Figure 6 Plot of residuals for response surface roughness for ordinary grinding wheel (left) and 3\% Nano $\mathrm{Al}_{2} \mathrm{O}_{3}$ nano Grinding wheel (Right)

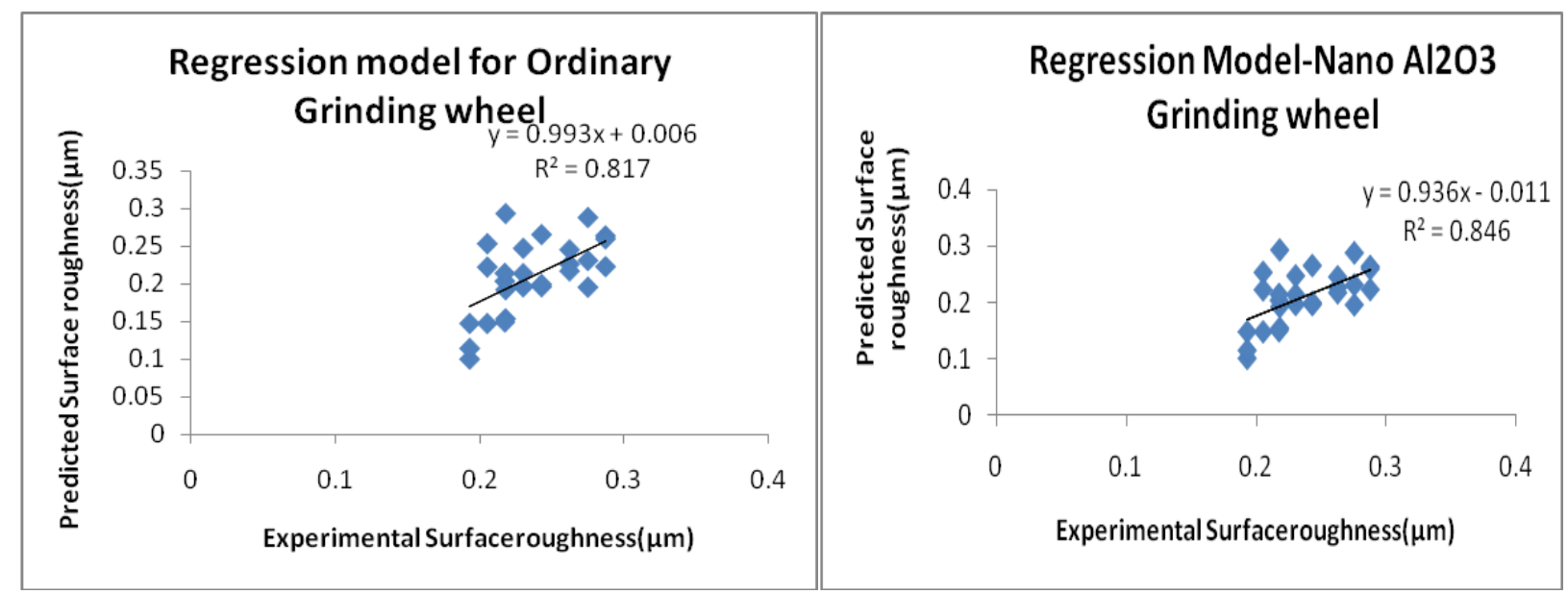

Figure 7 Regression model prediction for surface roughness for ordinary grinding wheel (left) and $3 \%$ Nano $\mathrm{Al}_{2} \mathrm{O}_{3}$ nano Grinding wheel (Right)

The regression plot for actual and predicted surface roughness values, for RSM model were shown in Figure 7. The regression coefficient values, for ordinary grinding wheel and 3\% $\mathrm{Al}_{2} \mathrm{O}_{3}$ Nano grinding models respectively, are 0.817 and 0.846 . These values reflect that the model has the confidence level, enough to predict the surface roughness for both grinding environments. RSM's prediction of Ti alloy surface finish showed better accuracy for $3 \% \mathrm{Al}_{2} \mathrm{O}_{3}$ nano wheel rather than for the ordinary grinding wheel. 


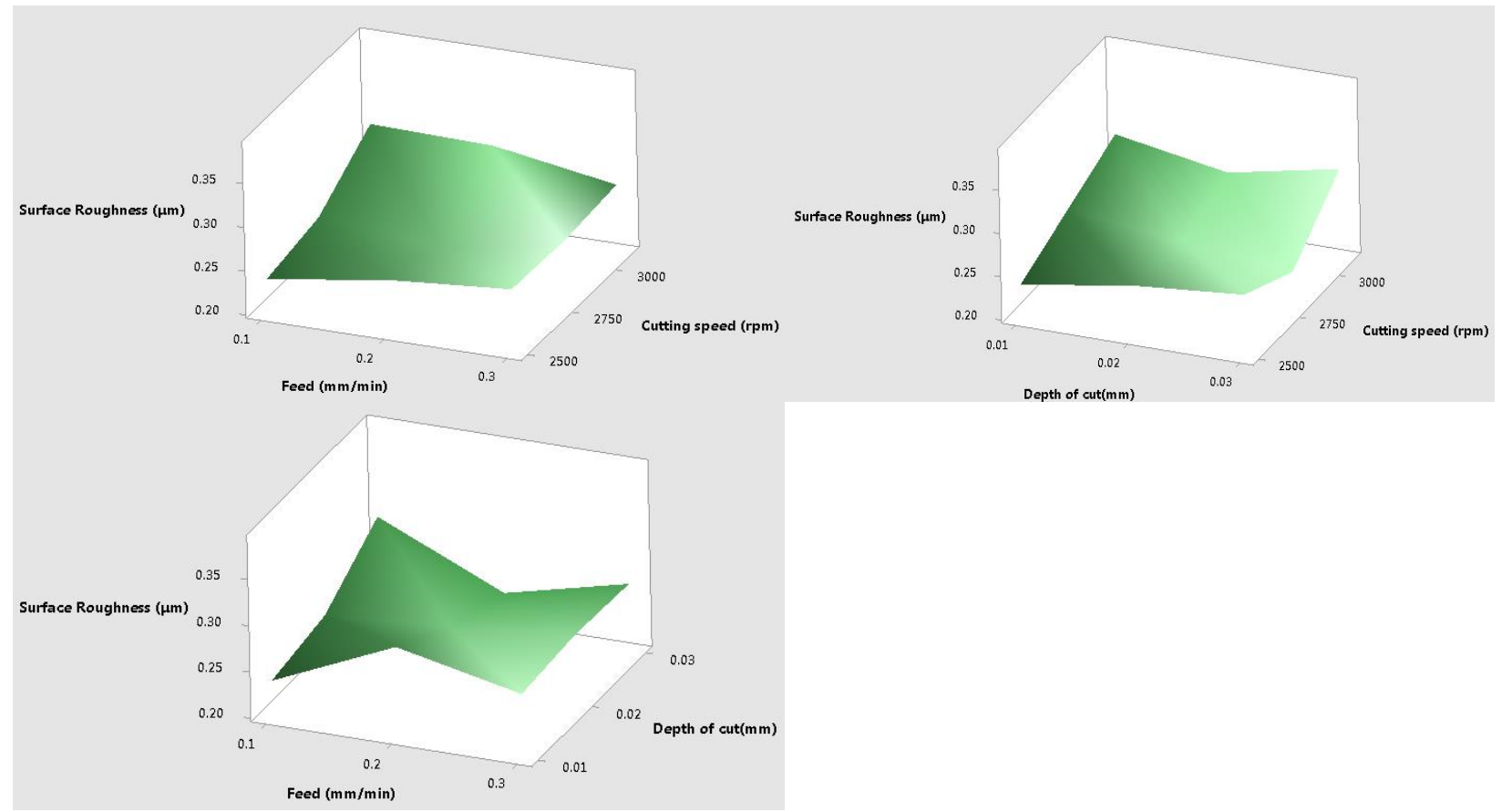

Figure 8 Three dimensional RS plots portrayed effects of two variables on surface roughness for ordinary grinding wheel. The third variable kept the center neutral level (i. Cutting feed and speed ii. Depth of cut and cutting speed; iii: Depth of cut and Feed)

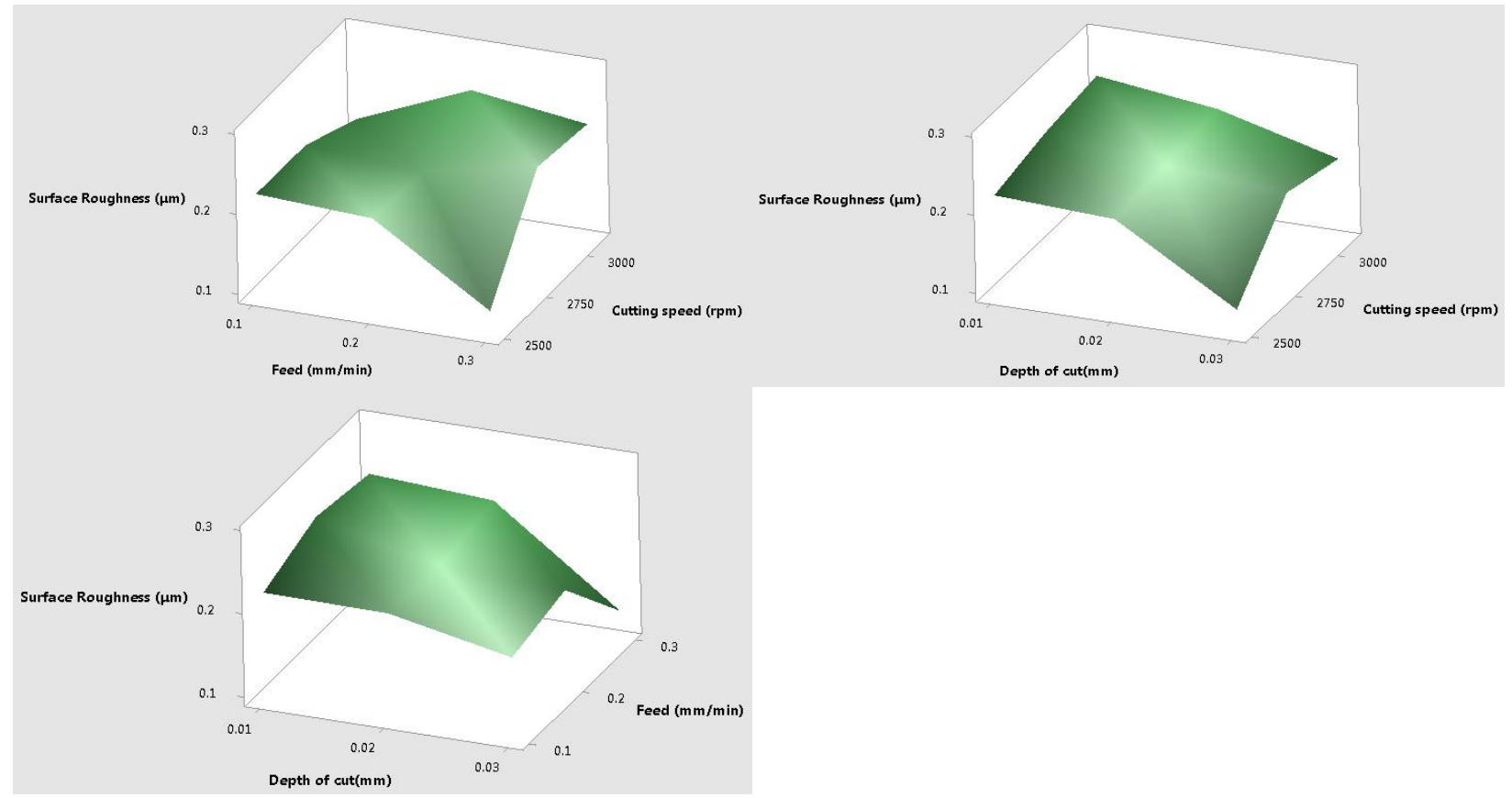

Figure 9 Three dimensional Response surface plots portrayed the effects of two variables on surface roughness for $3 \% \mathrm{Al}_{2} \mathrm{O}_{3}$ nano grinding wheel. The third variable kept the center neutral level (i. Cutting feed and speed ii. Depth of cut and cutting speed; iii: Depth of cut and Feed) 
Figures 6 and 7 portray 3D response surface plots for surface roughness of Ti alloy on grinding. Figure 6(i) show the relation of surface roughness with the feed rate and cutting speed while Figure 6 (ii) illustrates the relationship between cutting speed with depth of cut for measuring surface finish. For the $3 \% \mathrm{Al}_{2} \mathrm{O}_{3}$ nano grinding wheel, low feed with high cutting speed of wheel were found to be responsible for low surface roughness while high surface roughness was generated at high feed rates and medium depth of cut. For all the cases, the $\mathrm{Al}_{2} \mathrm{O}_{3}$ nano particles influenced heat absorption and force capacity of wheel, which in turn improved the surface finish of the ground Ti alloy.
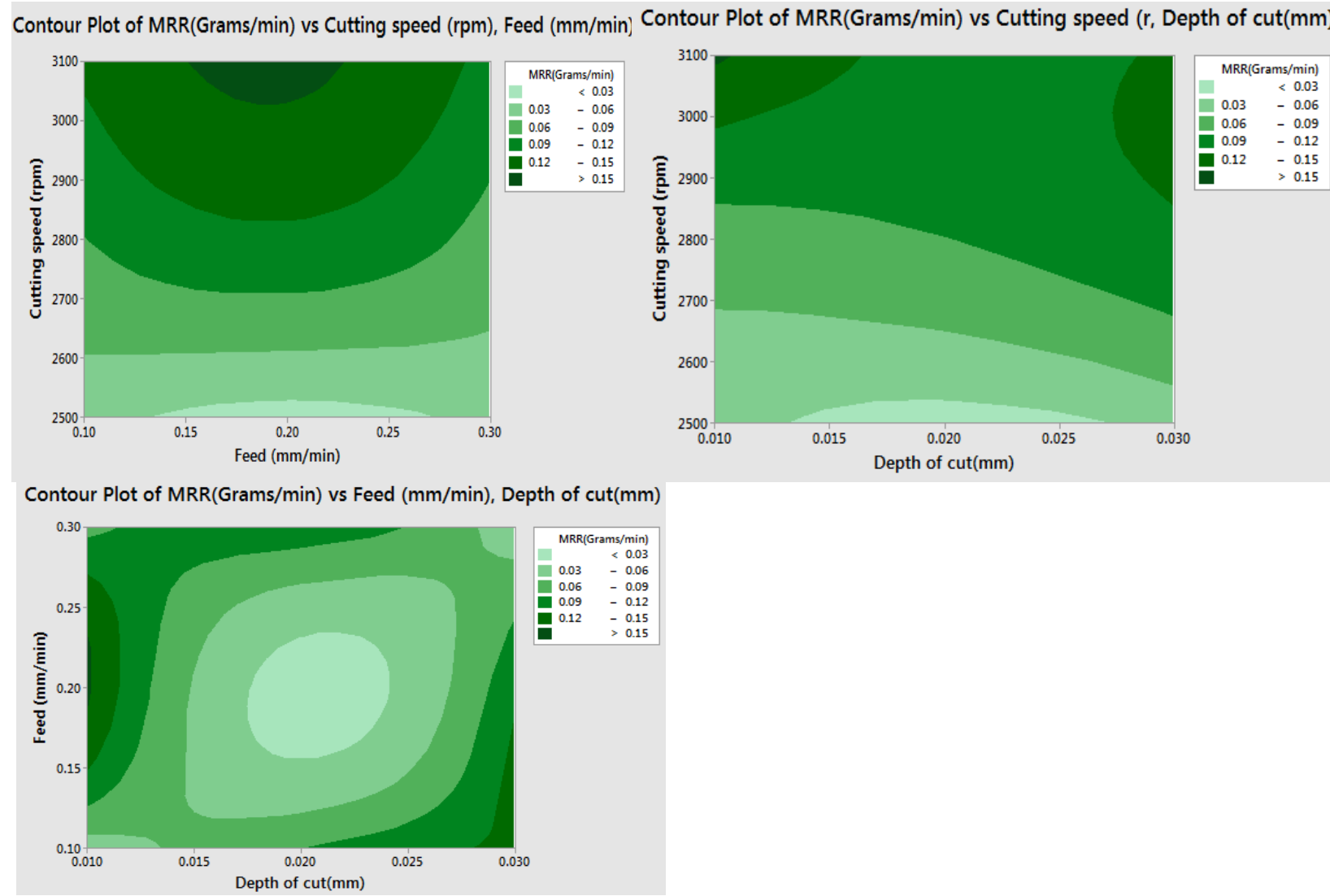

Figure 10 Three dimensional contour plots depicting the primary variables influencing surface roughness for ordinary grinding wheel and third less affected variable is kept at middle level.

(i. Cutting speed and feed; ii. Cutting speed and Depth of cut; iii. Feed and Depth of cut) 

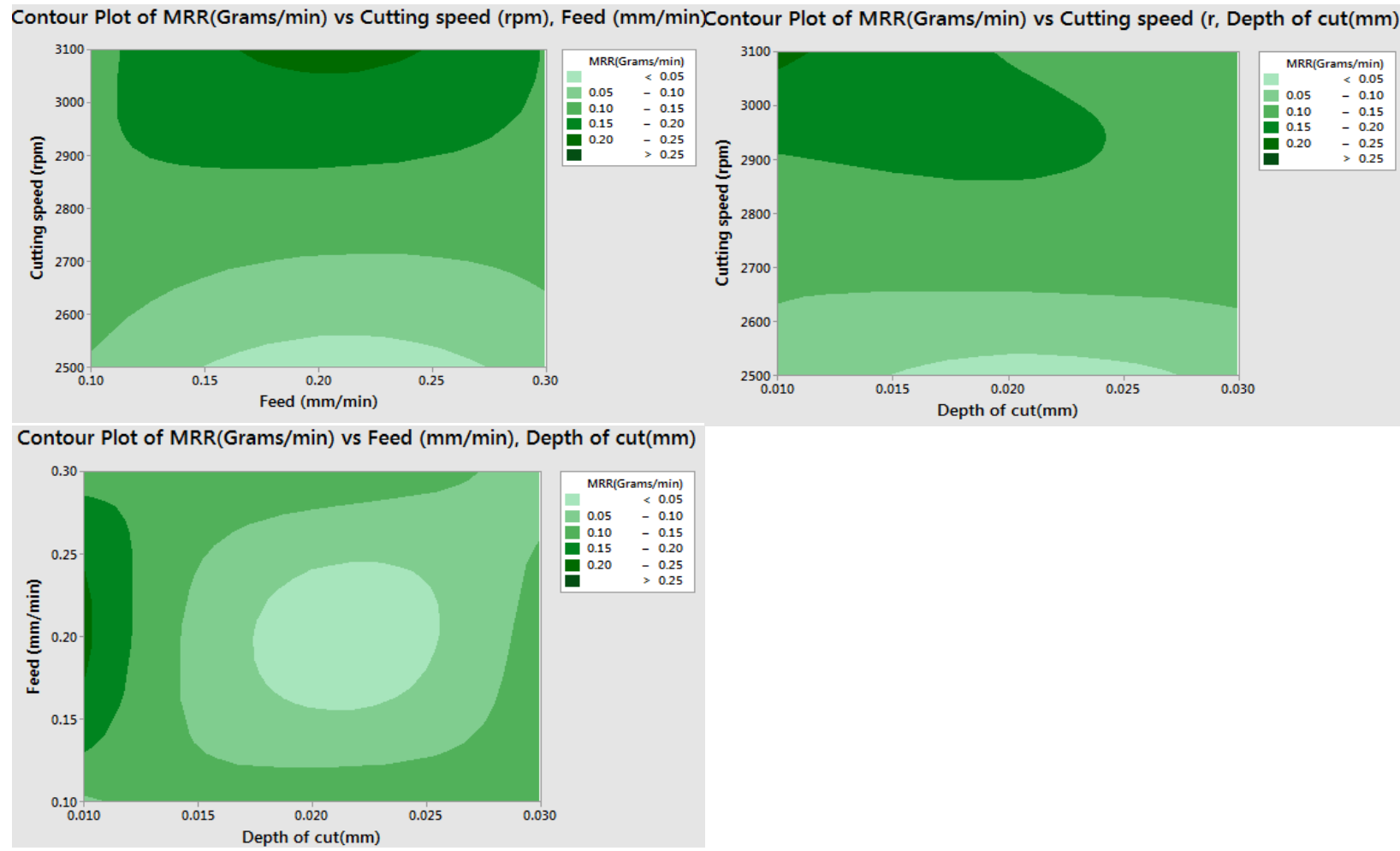

Figure 11 Three dimensional contour plots depicted the primary variables influencing surface roughness for $3 \%$ nano $\mathrm{Al}_{2} \mathrm{O}_{3}$ grinding wheel and third less affected variable is kept at middle level. (i. Cutting speed and feed; ii. Cutting speed and Depth of cut; iii. Feed and Depth of cut)

The contour plots as depicted in Figures 8 and 9, are symmetric for feed and depth of cut and the peaks are seen at the centre of the surface for $3 \% \mathrm{Al}_{2} \mathrm{O}_{3}$ nano grinding wheel. One independent variable of feed is taken on the vertical axis and other independent variable of depth of cut on the horizontal axis. The contour lines represents the response for surface roughness, dependent on input variables. The independent variables are usually restricted to a regular grid. More dark areas are present in the response for the ordinary grinding wheel as compared with the $3 \% \mathrm{Al}_{2} \mathrm{O}_{3}$ nano grinding wheel. The actual DOE technique to determine the correct response surface roughness variables are rather difficult and have been generated by the Minitab software.

\subsection{Neural Networks predictions for surface finish with $3 \% \mathrm{Al}_{2} \mathrm{O}_{3}$ nano grinding wheel.}

The neural network model was developed with respect to real grinding experiments for the exact prediction of output parameters like surface roughness and temperature. Normally neural networks are adopted for getting solution which less experimental data are available but here L27 orthogonal array was used to conduct experiments and their data were available. A lack of clarity still exists in finding optimum values and so neural network methods were opted for. Neural networks fundamentally connect input and output with various interconnecting nodes along with weights at the nodes as portrayed in Figure 12. Each neuron receives more input 
parameters and once the network architecture is chosen, the network is trained. $10 \%$ of the experimental data were used for validating the results.

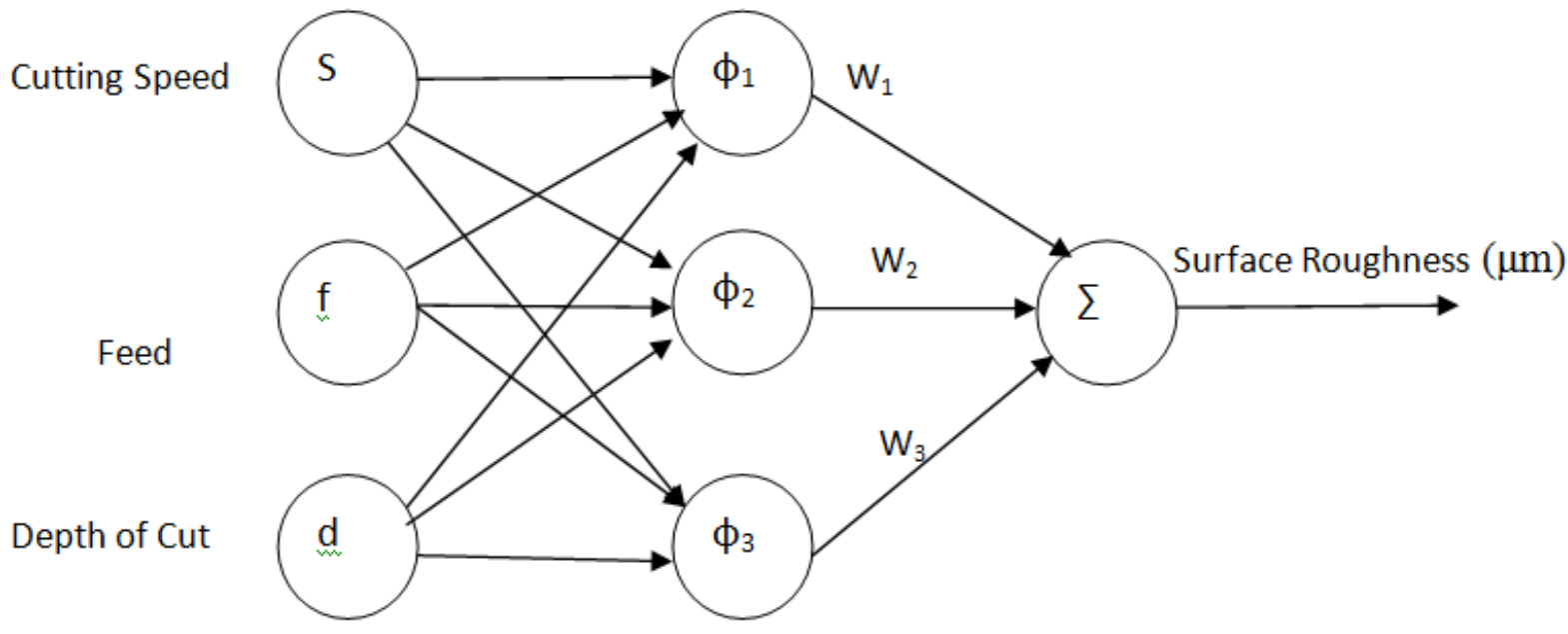

Input layer Hidden layer Output layer

Figure 12 Neural network architecture for nano grinding wheel machining

Feed forward back propagation algorithm is one of the most widely used algorithms to predict models accurately. This is done by adjusting weights to train the neural network (NN). NN has input, hidden and output layer where the weightage of each node is adjusted by using linear regression procedures so that results depict minimum error with $95 \%$ confidence. Every single input parameter of cutting feed, speed and depth of cut is represented and the coded values are sent with weights to the hidden layer. Next, the newly modified hidden layer values are sent to the output layer for summing up values and to be displayed as a single optimum parameter. Validation of the results are checked by running a vast number of iterations. If the number of iterations reach a default value then the training is stopped. In a majority of training cases, early stoppage occurs when less epochs have elapsed and normally 5\% values are kept for testing the models.
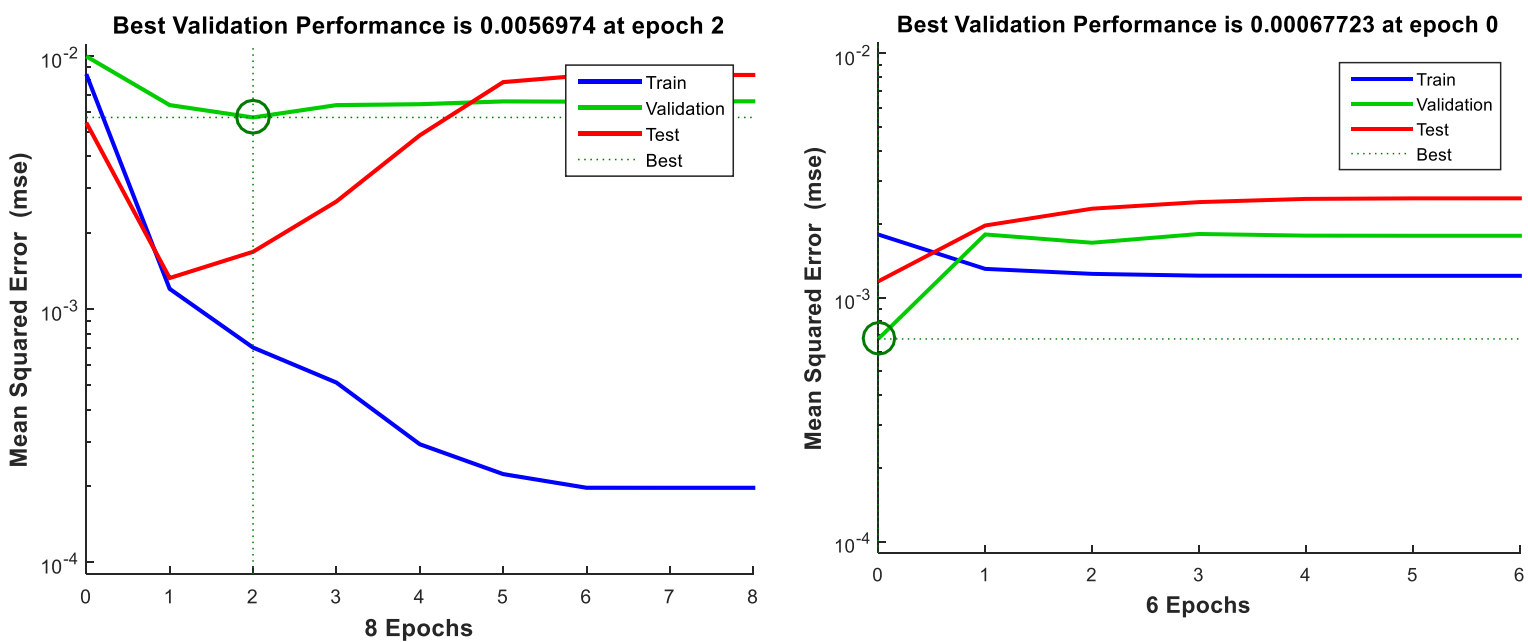
Figure 13 Mean square error for Normal grinding wheel (left) and Nano grinding wheel (Right)

Artificial Neural Network (ANN) is a powerful tool to predict complicated and congested response models like the grinding process. Back propagation (BP) neural network model is highly fitted for process modeling, as this has high tolerance for error and its capability to approximate connections between input and output variables is huge. Back propagation ANN is a multi layer network with highly skilled learning ability. Each of its three layers are formed by using several neurons and bias networks. Back propagation uses a gradient-descent algorithm to reduce MSE or mean square error, between the predicted values from the neural network model and target data of surface roughness as can be seen in Figure 13.

$$
\text { Mean Square Error(MSE)for Surface Roughness }=\frac{1}{N} \sum_{i=1}^{n}\left(e_{i}\right)^{2}=\frac{1}{N} \sum_{i=1}^{n}\left(T o_{i}-a o_{i}\right)^{2}
$$

Where $\mathrm{e}_{\mathrm{i}}$ is the error between ith input and output data pair in the sets of $\mathrm{N}$ input-output data pairs. Toi is the value predicted surface roughness value of $i^{\text {th }}$ output and aoi is the $i^{\text {th }}$ output from actual output of ANN.

Figure 13 shows the general view of testing, training and validation of $\mathrm{R}$ value for $3 \%$ $\mathrm{Al}_{2} \mathrm{O}_{3}$ nano grinding wheel, which is 0.90503 when compared with the ordinary wheel's performance of 0.86089 . Scatter plots have been drawn between targets with output parameters and indicate certain experiments with more deviation which in turn lead to poor fit with the linear values. The next step was to analyze these data, to see if they lay outside the training data set. Wherever more deviation was found, they were removed and new set of data for testing the set were included. Whenever the network was still not accurate, new networks were framed and the set trained again. Every time the feed forward network was initialized with target values and the network trained to get better solutions. 

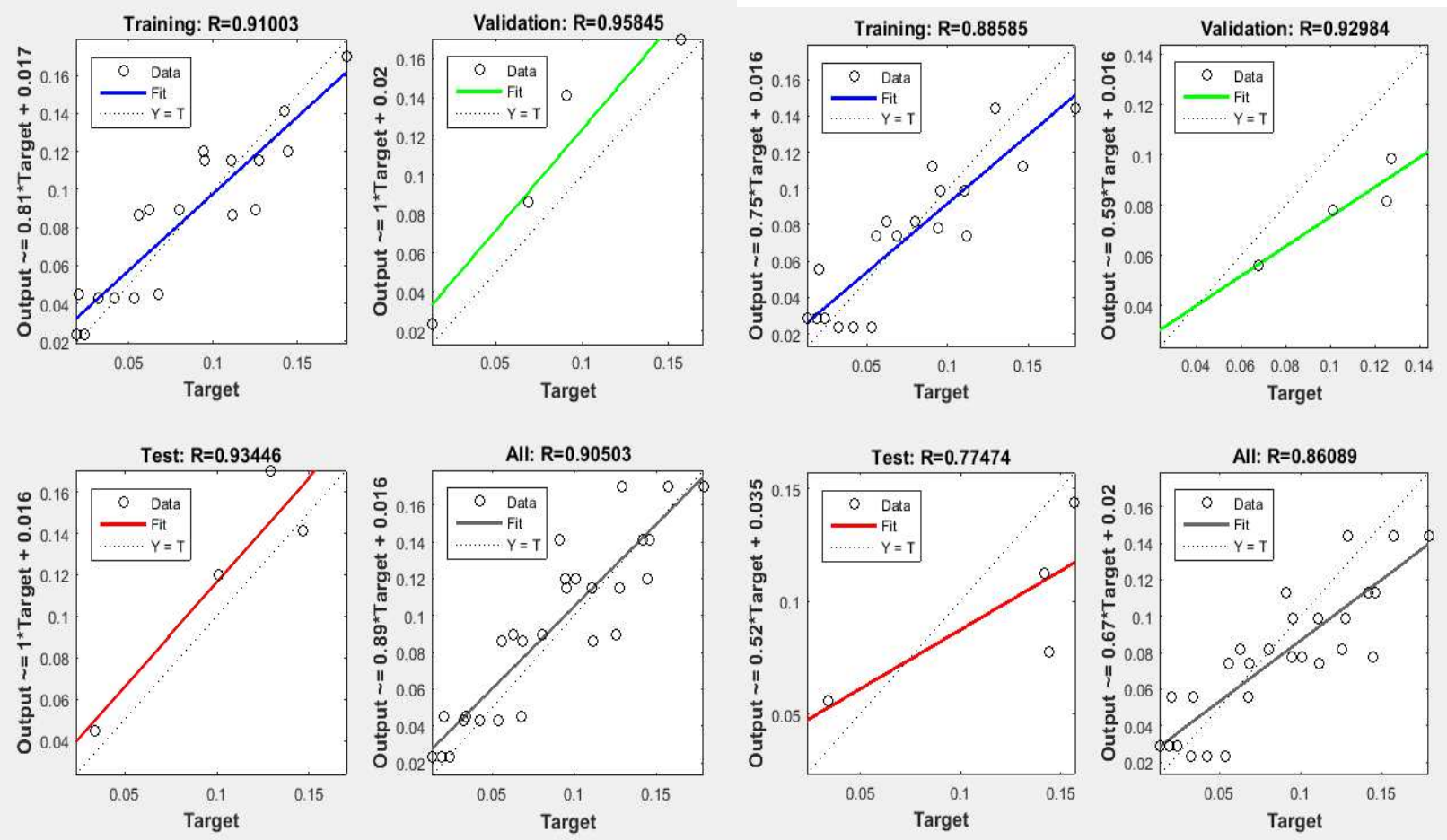

Figure 14 Liner regression plot with Neural network model and target data for output surface roughness
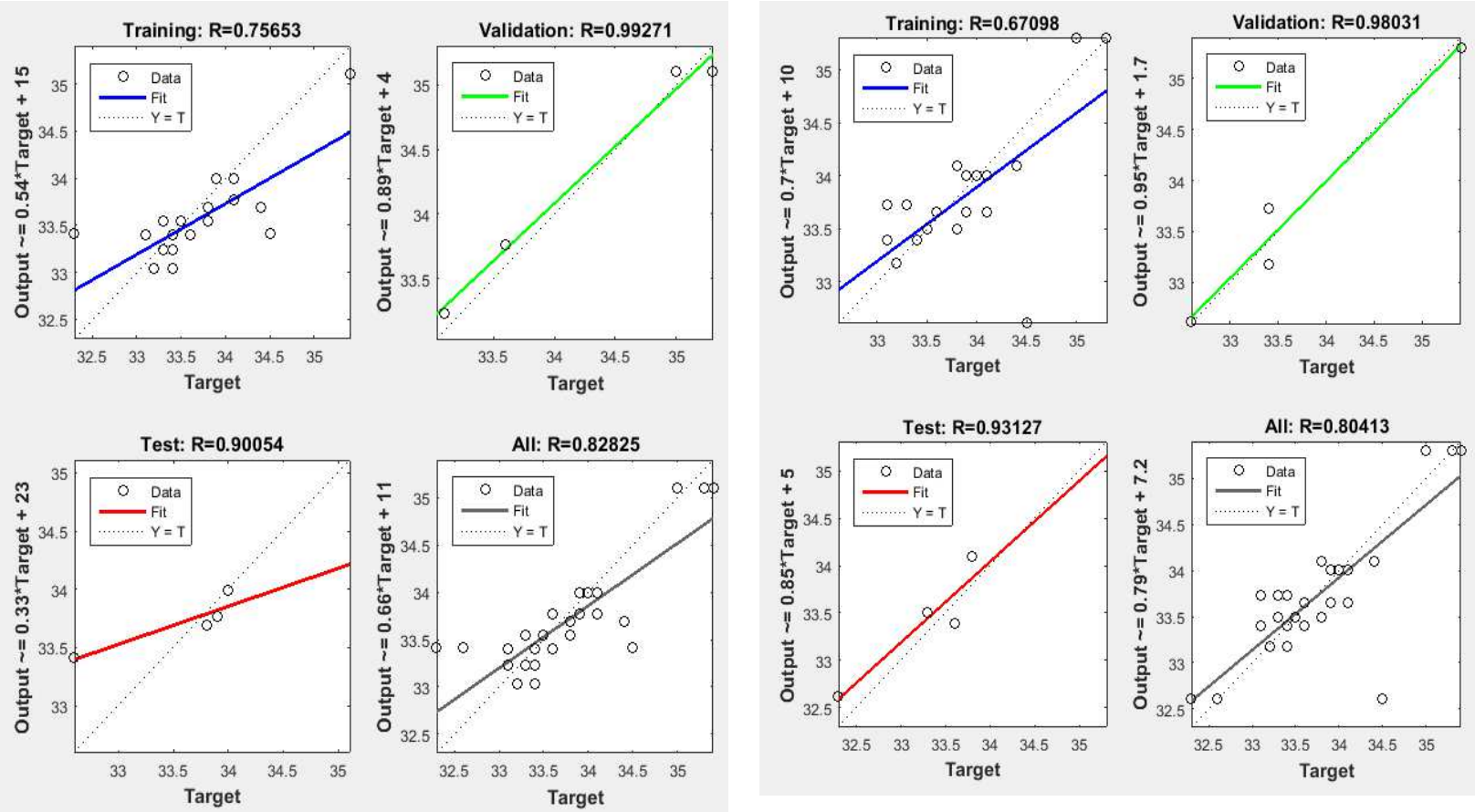

Figure 15 Temperature responses of $3 \% \mathrm{Al}_{2} \mathrm{O}_{3}$ nano grinding wheel (left) and Ordinary Grinding wheel (Right) 
Figure 15 showed temperature response for nano grinding wheel with an $\mathrm{R}$ value of 0.82825 , when compared with the ordinary grinding wheel which was 0.80413 . This model fit very well with lower errors than any other model.

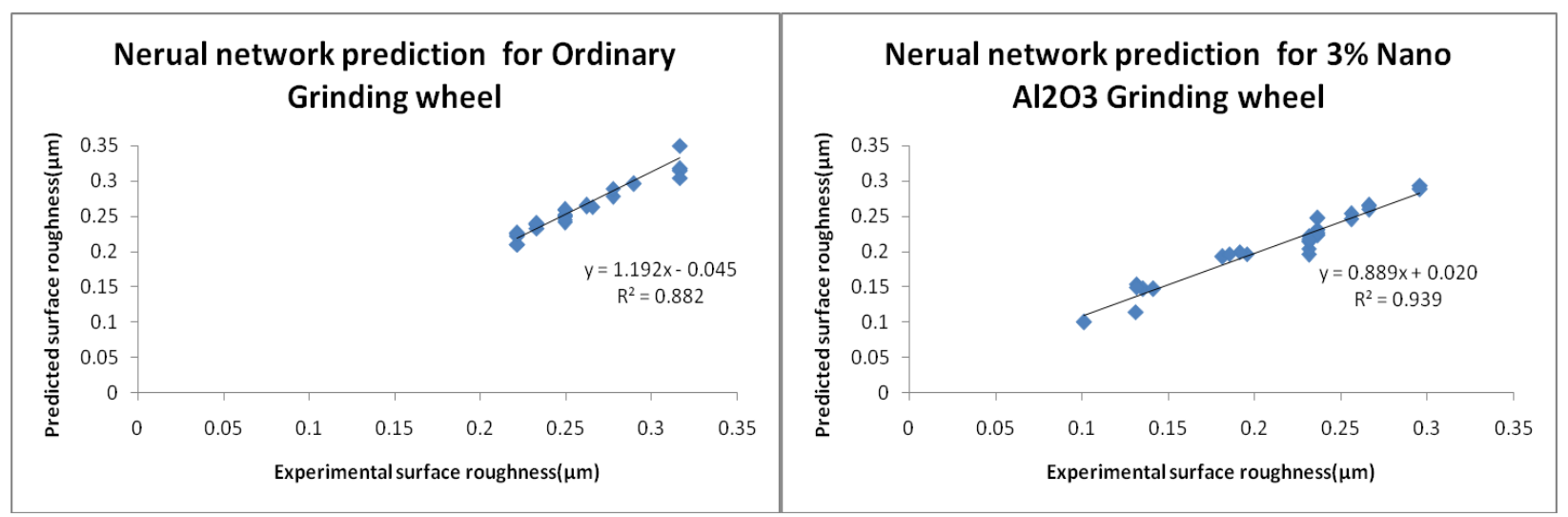

Figure 16 Neural network surface roughness prediction model for grinding wheels with and without $3 \% \mathrm{Al}_{2} \mathrm{O}_{3}$ nano powder

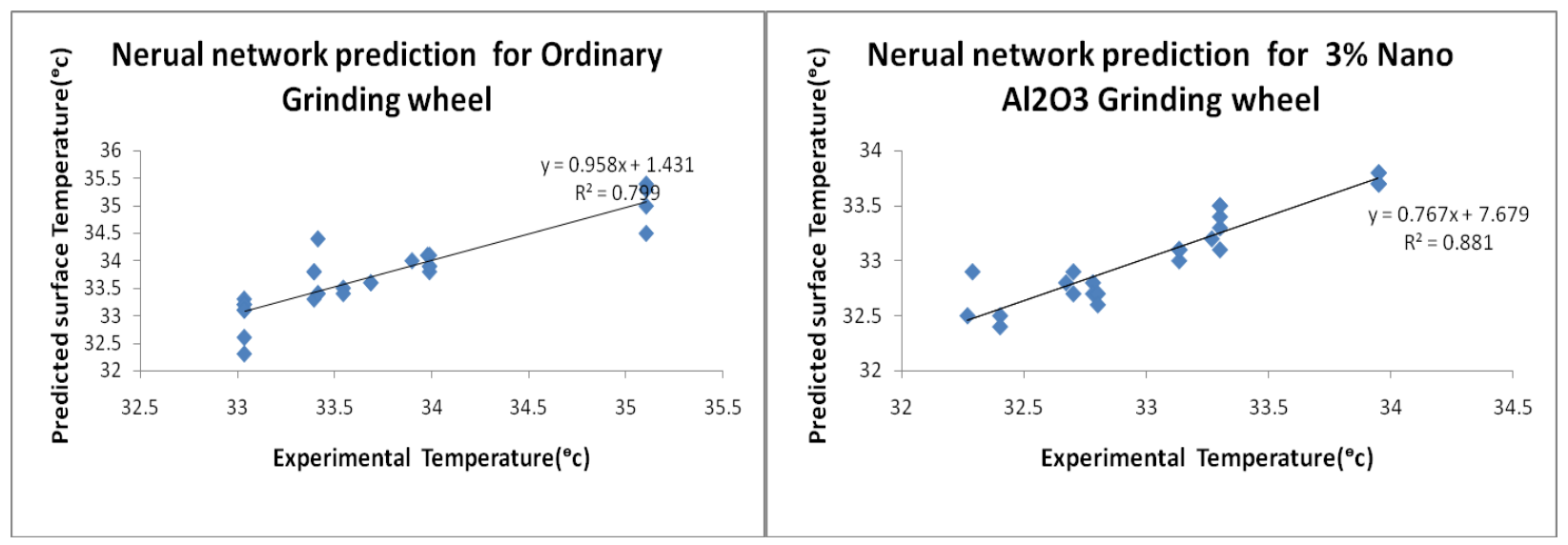

Figure 17 Neural network surface temperature prediction model for ordinary grinding wheel and $3 \% \mathrm{Al}_{2} \mathrm{O}_{3}$ nano grinding wheel

Figures 16 and 17 portray mean square error analysis for the predictive model neural network for surface roughness in contrast with experimental values. The $\mathrm{R}^{2}$ value for grinding efficiency is 0.881 . High $\mathrm{R}^{2}$ value indicate that using nano grinding wheel based machining applications fit the model better.

3.5. Comparison of response surface modeling with artificial neural network for nano ground surface roughness and temperature

Of late, response surface methodology experimentation has been fitted with artificial neural network method to search for the most suitable grinding process. The method reveals both efficiency of the process response with respect to input variables as well as the interaction effect of the parameters. RSM and NN modeling tools are capable of solving non-linear and multivariable regression models and the ANN with RSM model developed from experimental data, correlated excellently. It had surface roughness R-values as 0.817 and 0.882 for ordinary 
grinding wheel surface finish when compared with $3 \% \mathrm{Al}_{2} \mathrm{O}_{3}$ nano grinding wheel values of 0.846 and 0.939 respectively. These grinding results depicted that neural network results had particularly low deviation from RSM due to inaccurate experimental data. The regression model coefficient was very well exhibited using RSM second order model. The RSM model was powerful enough to identify insignificant factors which affected second order models and thereby made it possible to minimize complexity. The comparison of predicted value of RSM and ANN with the experimental values have been illustrated. The results showed that predicted values of average roughness, had a 95\% confidence interval with readings recorded experimentally. Whatever variations still persisted in the experimental RSM and ANN model, were due to vibrational effects and noise factors of the wheel during the grinding process.

\section{Conclusions}

Surface roughness prediction model for $3 \% \mathrm{Al}_{2} \mathrm{O}_{3}$ nano grinding wheel, to grind Ti alloy surfaces was developed using Response Surface Methodology (RSM) and Artificial Neural Network (ANN) methodology and the following results were assimilated during the process:

1. The values of the regression coefficient, for ordinary grinding wheel and $3 \% \mathrm{Al}_{2} \mathrm{O}_{3}$ Nano grinding models respectively, were 0.817 and 0.846 and these values reflect that the model was adequate to predict surface roughness for both the grinding environments. RSM showed better accuracy for $3 \% \mathrm{Al}_{2} \mathrm{O}_{3}$ nano wheel than for the ordinary wheel when predicting surface finish of Ti alloy.

2. Residual value nearer to 1 meant that RSM model was better and fit exactly with the output data. The overall R-Sq value was 0.90503 for $3 \% \mathrm{Al}_{2} \mathrm{O}_{3}$ nano grinding wheel when compared with ordinary wheel performance of 0.86089 . This meant that lower training error with good output values fit model ideally.

3. The RSM and ANN models constructed from experimental data correlated well and had surface roughness R-values of 0.817 and 0.882 for the ordinary grinding wheel, when compared with the $3 \% \mathrm{Al}_{2} \mathrm{O}_{3}$ nano grinding wheel, which had $\mathrm{R}$-values of 0.846 and 0.939 respectively. These grinding results illustrate that ANN prediction had greater deviation than RSM prediction values.

4. When the $3 \% \mathrm{Al}_{2} \mathrm{O}_{3}$ Nanopowder grinding wheel was used at high cutting conditions, it lead to the reduction of wheel temperature by $5.94 \%$, which directly influenced the surface finish of Ti alloy and tool life of the grinding wheel.

\section{Availability of data and materials:}

The data supporting the conclusions is reported in this manuscript. Therefore, no additional data is required to be attached.

Competing interests: The authors declared that they have no competing Interests.

Funding: Not applicable

Authors' contributions: Deborah Serenade Stephen plan and executed the experimental work and participated the manuscript writing. 
Sethuramalingam Prabhu conducted the RSM and ANN modeling work. All authors read and approved the final manuscript.

Acknowledgements: The authors are thankful to Machine shop of Department of Mechanical Engineering, SRMIST for providing the experimental facilities.

\section{References}

[1] Hao Nan Li and Dragos Axinte, "Textured grinding wheels: A review", International Journal of Machine Tools \& Manufacture, Vol.109, 2016, pp.8-35.

[2] Ryszard wojcik, "The grinding of Titanium alloys", Archives of Mechanical technology and automation, Vol.33, No.4, 2013, pp.49-60.

[3] Ryszard wojcik The Effect of Grinding in Titanium Alloy Deformation", Mechanics and Mechanical Engineering Vol. 17, No. 4 (2013) 309-315.

[4] Wheel Li Xun, Chen Zhitong, Chen Wuyi, "Suppression of Surface Burn in Grinding of Titanium Alloy TC4 Using a Self-inhaling Internal Cooling”, Chinese Journal of Aeronautics, 24 (2011) 96-101

[5] You, Jiali, Carbon nanotube grinding wheel for nano machining of engineering and biomedical materials, Thesis,Hong Kong University of Science and Technology, 2009.

[6] Prabhu S, Vinayagam BK., "AFM investigation in grinding process with nanofluids using Taguchi analysis", International Journal of Advanced Manufacturing Technology, 2012, Vol. 60 Issue 1-4, pp.149-160.

[7] Chandrasekaran M, Devarasiddappa D, "Artificial neural network modeling for surface roughness prediction in cylindrical grinding of $\mathrm{Al}-\mathrm{SiCp}$ metal matrix composites and ANOVA analysis", Advances in Production Engineering \& Management, Vol.9(2),2014, pp.59-70.

[8] Davim.J.P, "Design of Experiments in production engineering”,2016, IX,pp.1-61,Springer, ISBN-9783319-238371.

[9] Daria Sidorenko, Leon Mishnaevsky Jr., Evgeny Levashov, Pavel Loginov, Mikhail Petrzhik, "Carbon nanotube reinforced metal binder for diamond cutting tools", Materials \& Design, Vol.83,2015, pp.536-544.

[10] Dinesh Setti, Sudarasan Ghosh, and P. Venkateswara Rao, "Application of Nano Cutting Fluid under Minimum Quantity Lubrication (MQL) Technique to Improve Grinding of Ti-6Al4V Alloy," International Journal of Mechanical, Aerospace, Industrial, Mechatronic and Manufacturing Engineering Vol:6, No:10, 2012.

[11] Salman Pervaiz, Amir Rashid, Ibrahim Deiab \& Mihai Nicolescu, Influence of Tool Materials on Machinability of Titanium- and Nickel-Based Alloys: A Review, Journal 
Materials and Manufacturing Processes, Volume 29, 2014 - Issue 3 Pages 219-252

[12] M. Modi, G. Agarwal, "Design, Development \& Experimental Investigation of ElectroDischarge Diamond Surface Grinding of Ti-6Al-4V", Advanced Materials Research, Vols. 418420, pp. 1478-1481, 2012.

[13] Suleyman Neseli , Dlhan Asilturk, and Levent Celik, "Determining the optimum process parameter for grinding operations using robust process", Journal of Mechanical Science and Technology 26 (11) (2012) 3587 3595.

[14] Chaojie Liu,Wenfeng Ding,Zheng Li, Changyong Yang, "Prediction of high-speed grinding temperature of titanium matrix composites using BP neural network based on PSO algorithm", Int J Adv Manuf Technol (2017) 89:2277-2285.

[15] Deng.Z.H, Zhang, X.H, Liu.W, Cao.H, “ A hybrid model using genetic algorithm and neural network for process parameters optimization in NC camshaft grinding", Int J Adv Manuf Technol (2009) 45:859-866. 
Figures

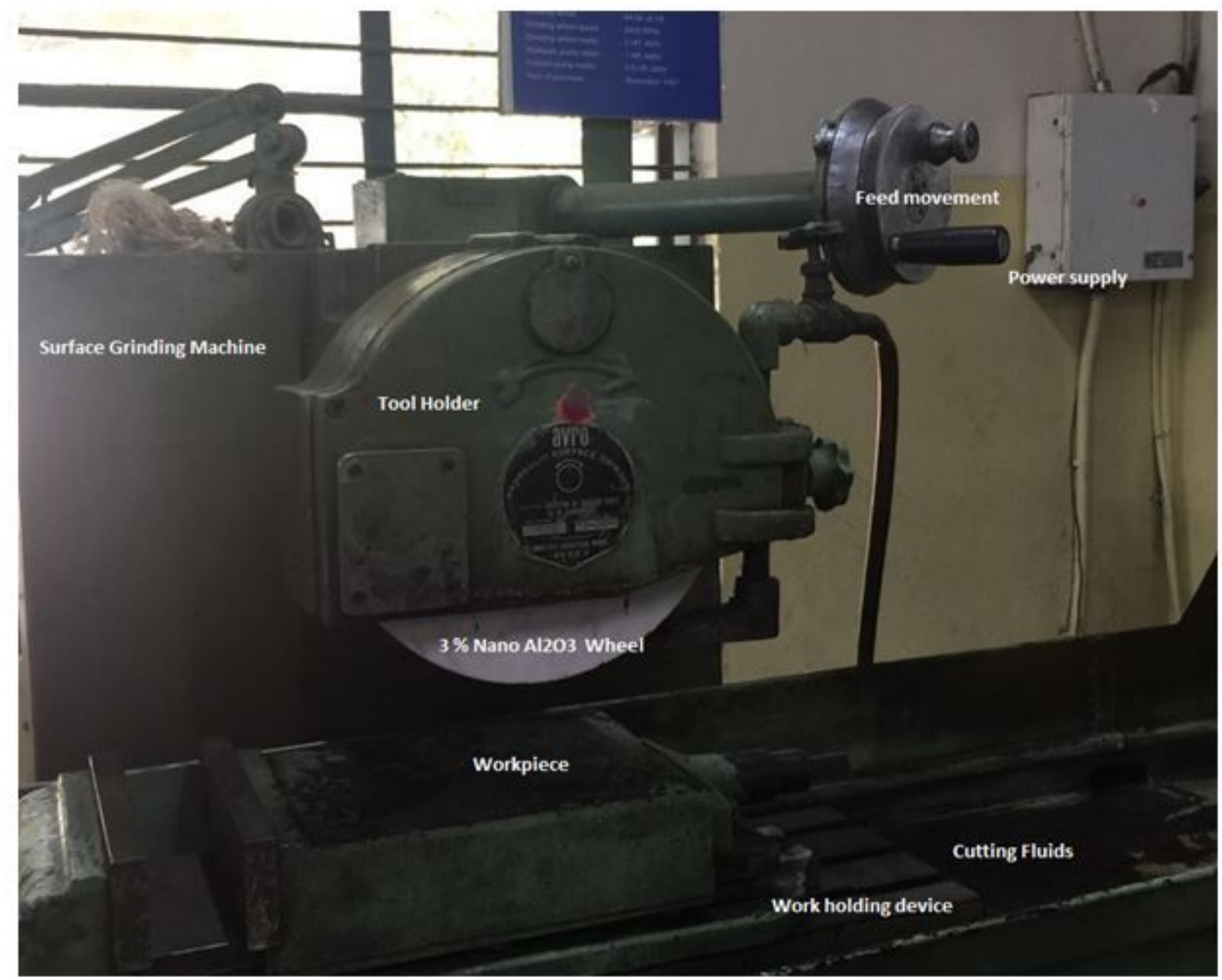

Figure 1

Surface Grinding Machine 


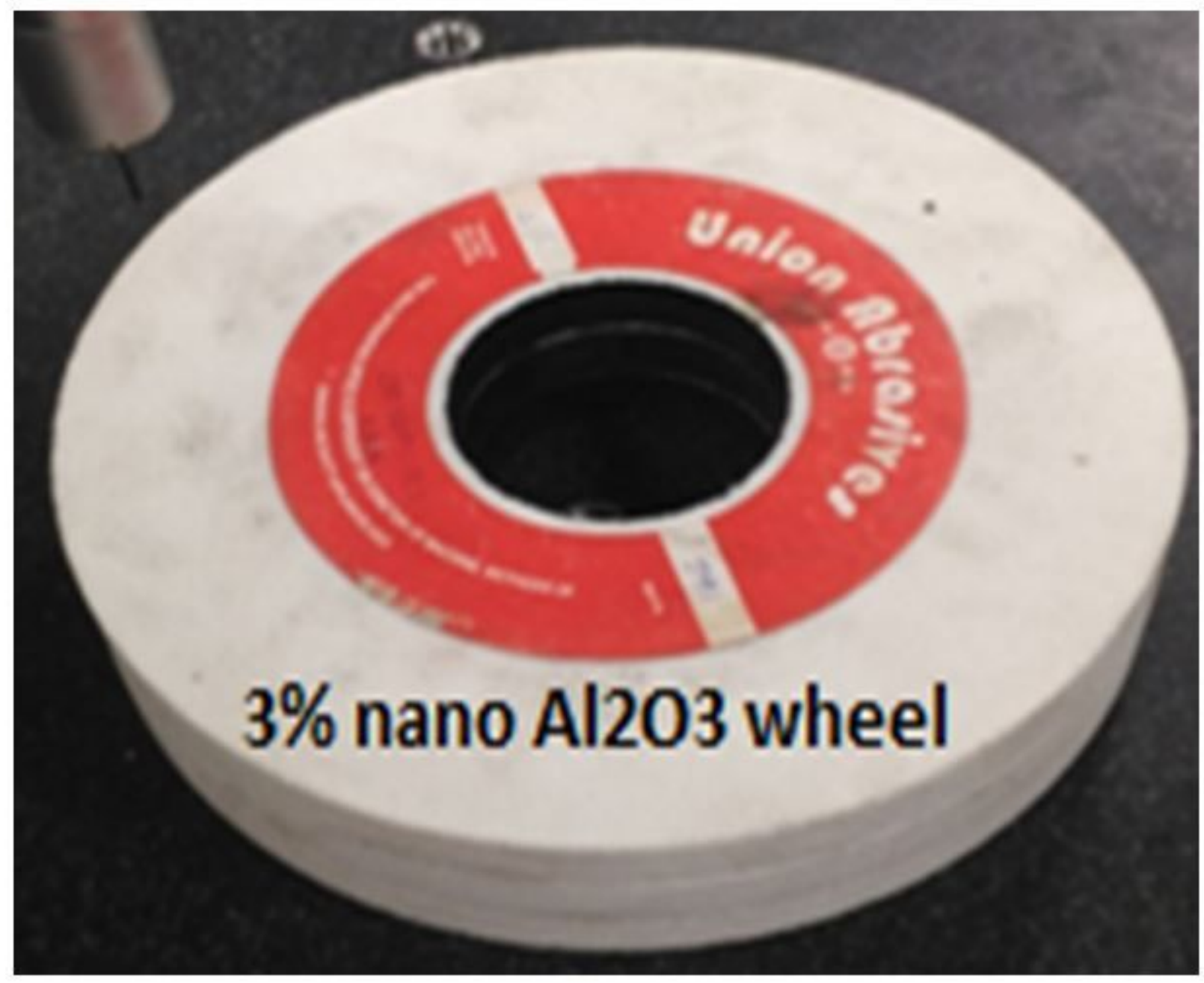

Figure 2

Nano Grinding wheel 

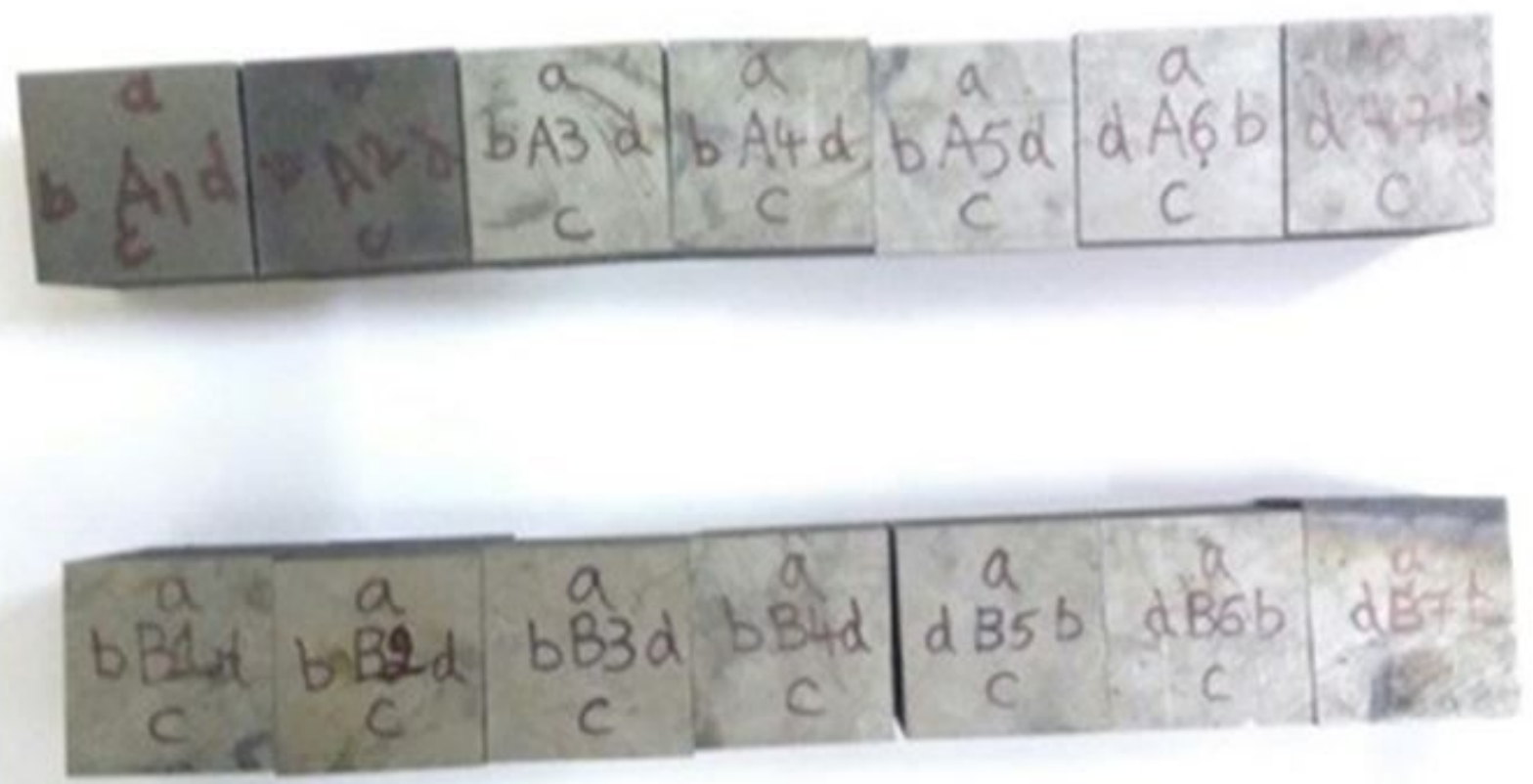

Figure 3

Ti-6Al-4V work pieces 


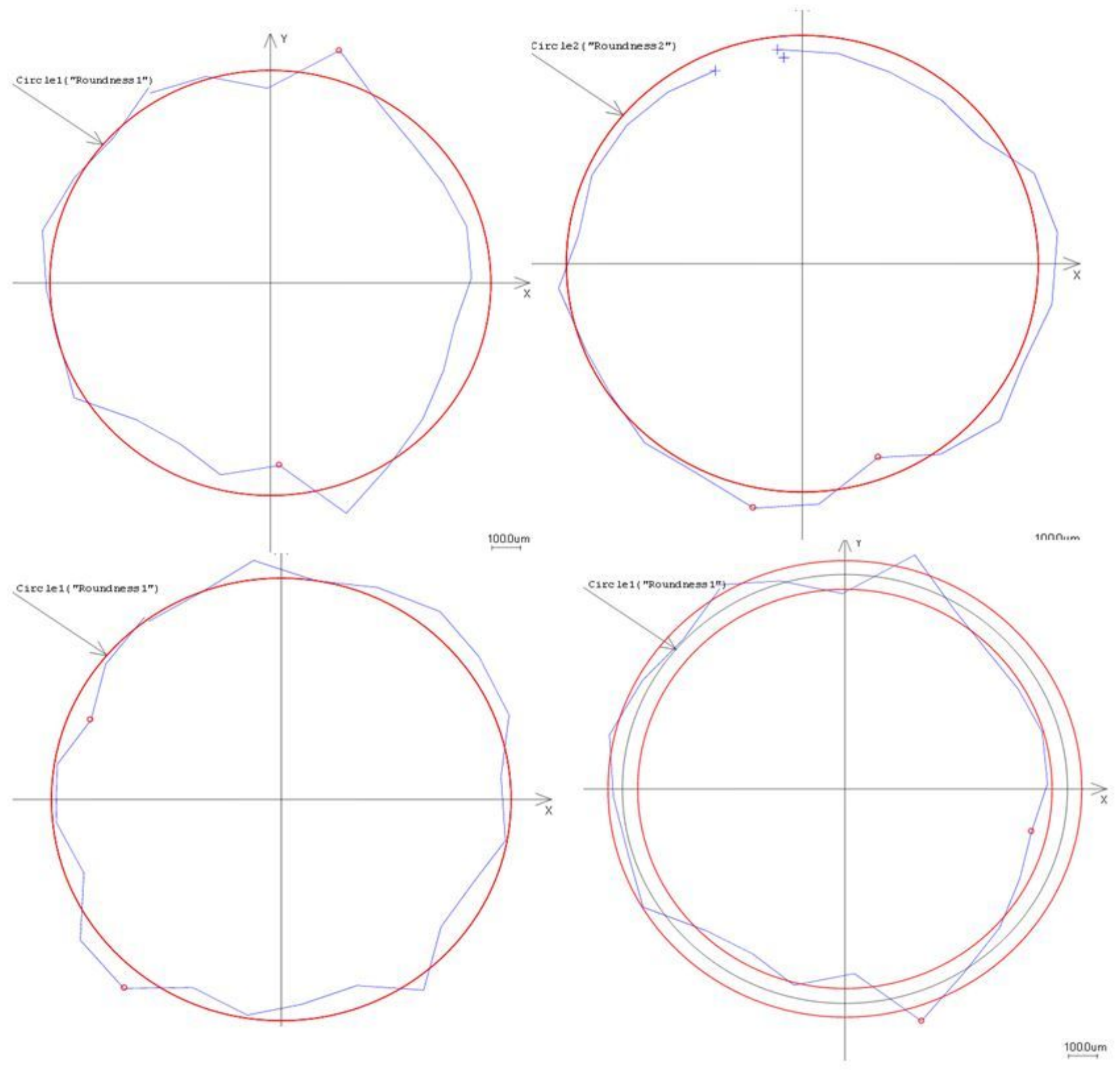

Figure 4

Circularity error of grinding wheel for a) Ordinary Grinding wheel before Grinding, $0.2128 \mu \mathrm{m}, \mathrm{b}$ ) Ordinary Grinding wheel after Grinding $0.1369 \mu \mathrm{m} \mathrm{c)} \mathrm{3 \%} \mathrm{Nano} \mathrm{Al203} \mathrm{Grinding} \mathrm{wheel} \mathrm{before} \mathrm{Grinding} 0.2093 \mu \mathrm{m} \mathrm{d}$ ) $3 \%$ Nano Al203 Grinding wheel after Grinding $0.098 \mu \mathrm{m}$. 

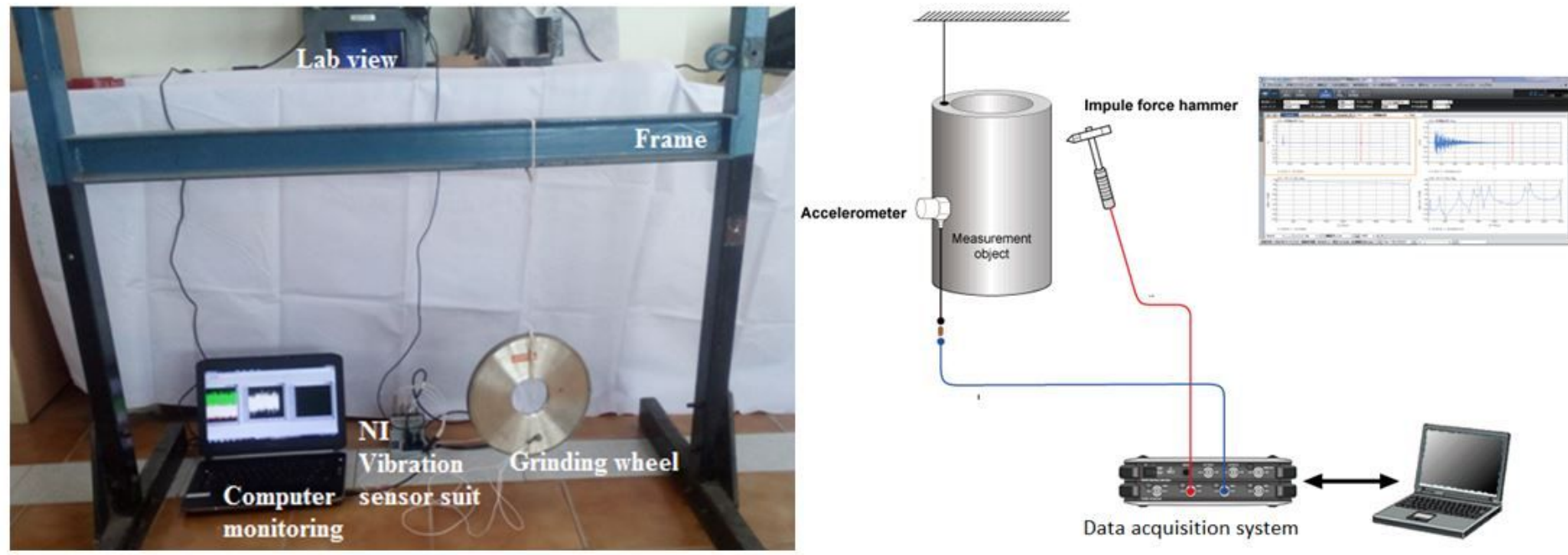

\section{Figure 5}

Experimental vibration analysis of the $3 \%$ Nano Al2O3 grinding wheel (left) and NI cDAQ setup with lab view analysis (Right)

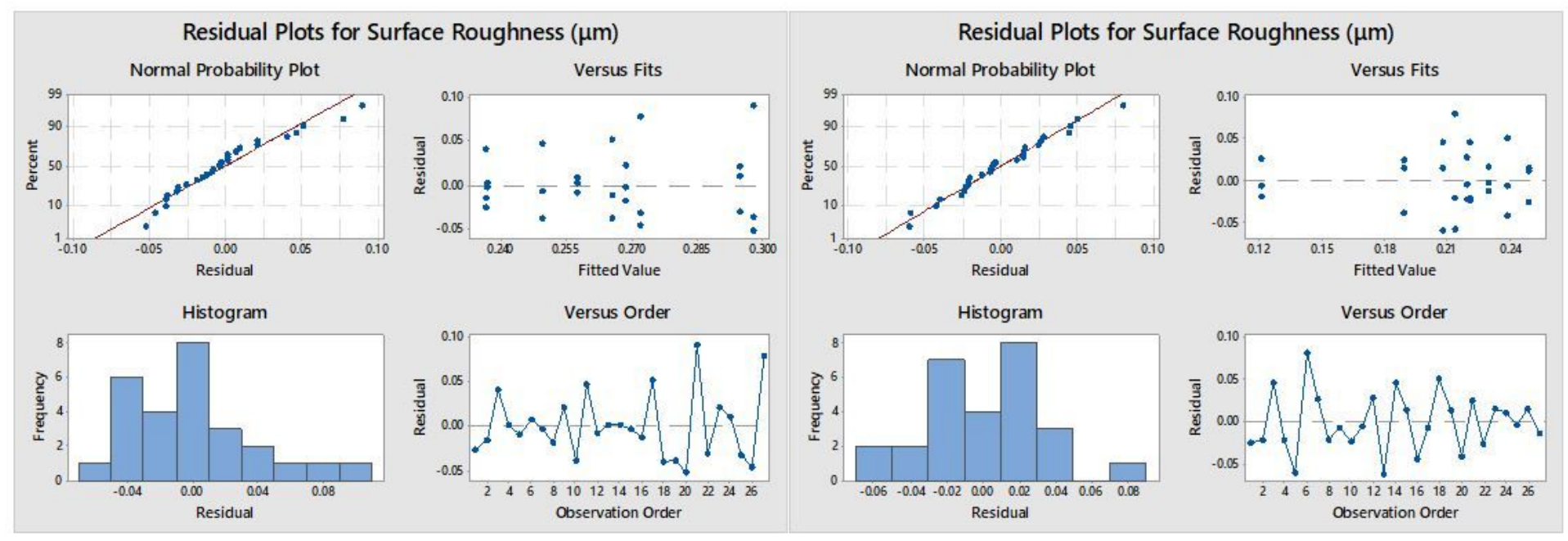

Figure 6

Plot of residuals for response surface roughness for ordinary grinding wheel (left) and 3\% Nano Al2O3 nano Grinding wheel (Right) 


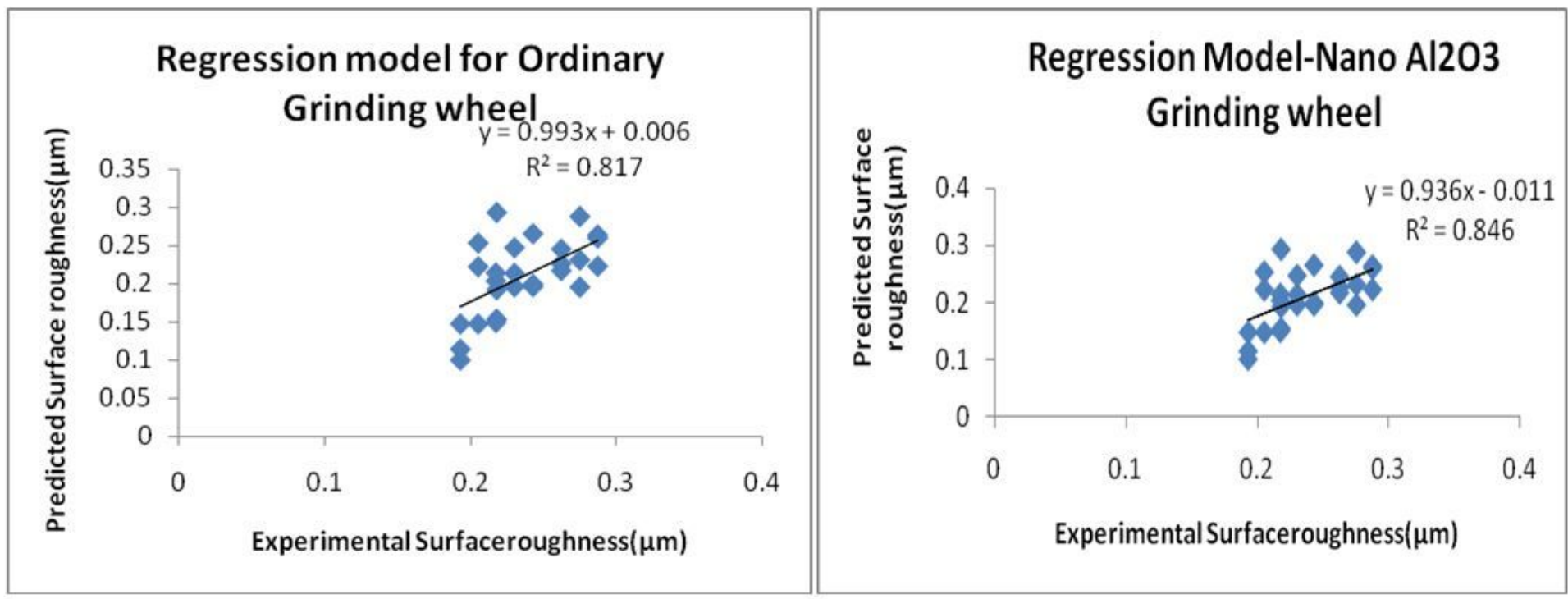

\section{Figure 7}

Regression model prediction for surface roughness for ordinary grinding wheel (left) and 3\% Nano Al2O3 nano Grinding wheel (Right)

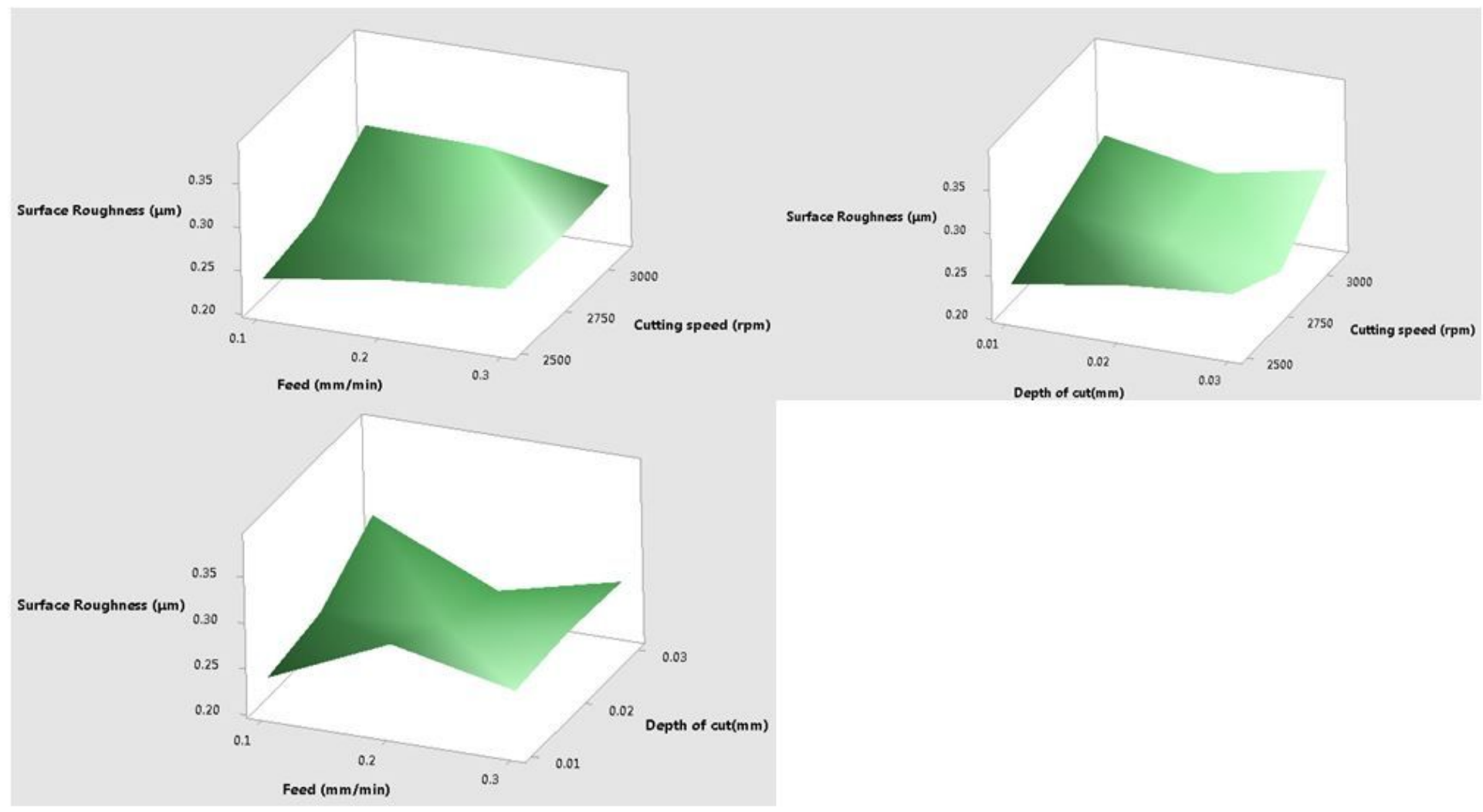

\section{Figure 8}

Three dimensional RS plots portrayed effects of two variables on surface roughness for ordinary grinding wheel. The third variable kept the center neutral level (i. Cutting feed and speed ii. Depth of cut and cutting speed; iii: Depth of cut and Feed) 


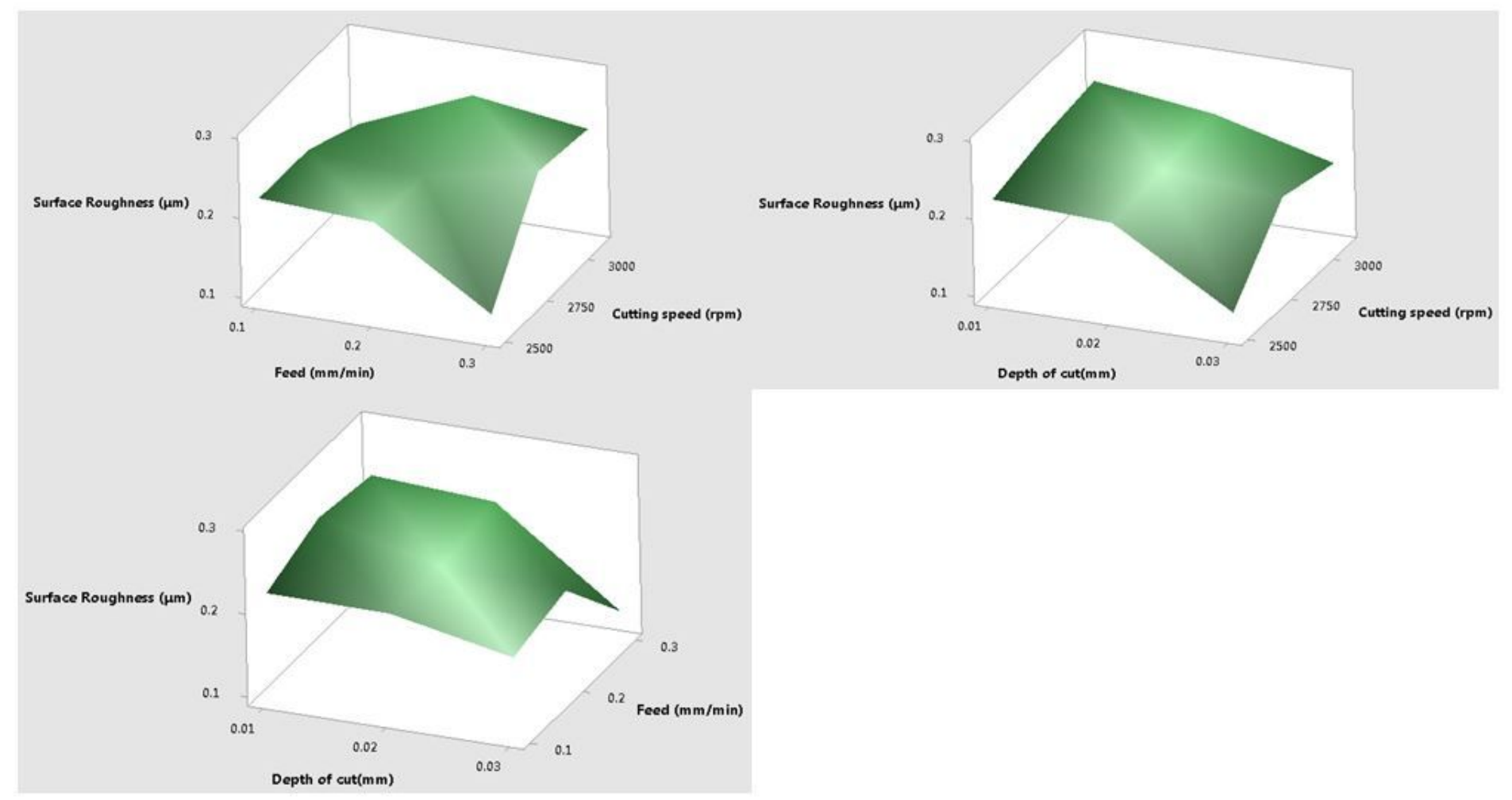

\section{Figure 9}

Three dimensional Response surface plots portrayed the effects of two variables on surface roughness for 3\% Al2O3 nano grinding wheel. The third variable kept the center neutral level (i. Cutting feed and speed ii. Depth of cut and cutting speed; iii: Depth of cut and Feed) 
Contour Plot of MRR(Grams/min) vs Cutting speed (rpm), Feed ( $\mathrm{mm} / \mathrm{min})$ Contour Plot of MRR(Grams/min) vs Cutting speed (r, Depth of cut(mm)
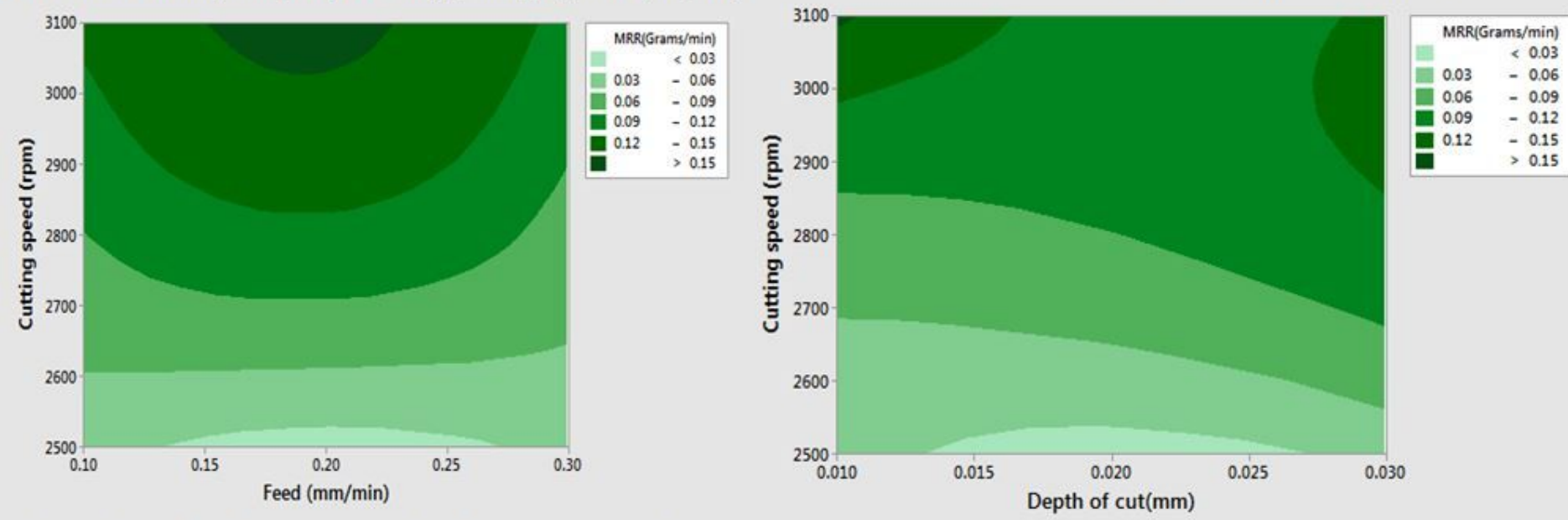

Contour Plot of MRR(Grams/min) vs Feed $(\mathrm{mm} / \mathrm{min})$, Depth of cut( $\mathrm{mm})$

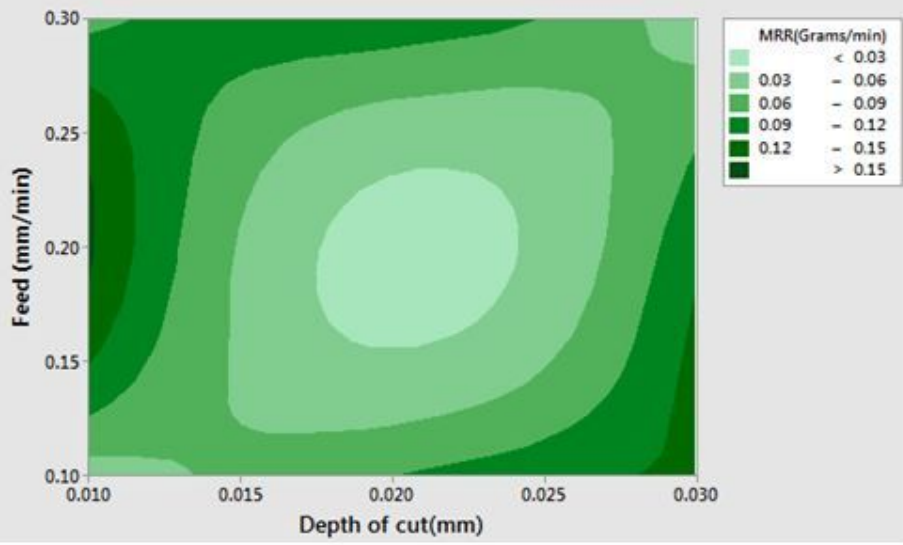

\section{Figure 10}

Three dimensional contour plots depicting the primary variables influencing surface roughness for ordinary grinding wheel and third less affected variable is kept at middle level. (i. Cutting speed and feed; ii. Cutting speed and Depth of cut; iii. Feed and Depth of cut) 
Contour Plot of MRR(Grams/min) vs Cutting speed (rpm), Feed ( $\mathrm{mm} / \mathrm{min}$ )Contour Plot of MRR(Grams/min) vs Cutting speed (r, Depth of cut(mm)
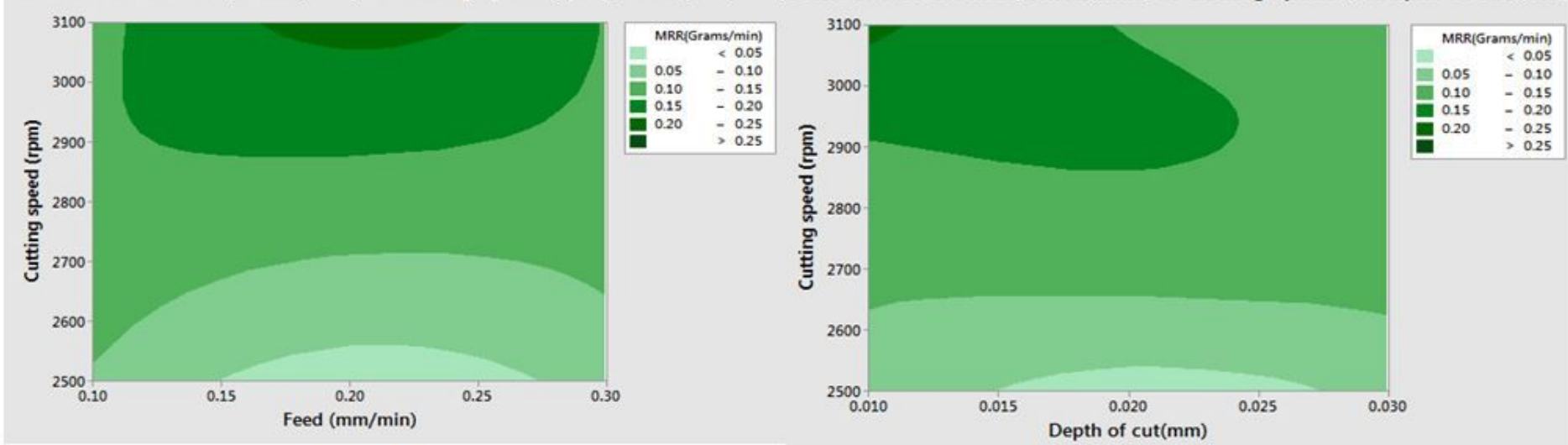

Contour Plot of MRR(Grams/min) vs Feed ( $\mathrm{mm} / \mathrm{min})$, Depth of cut(mm)

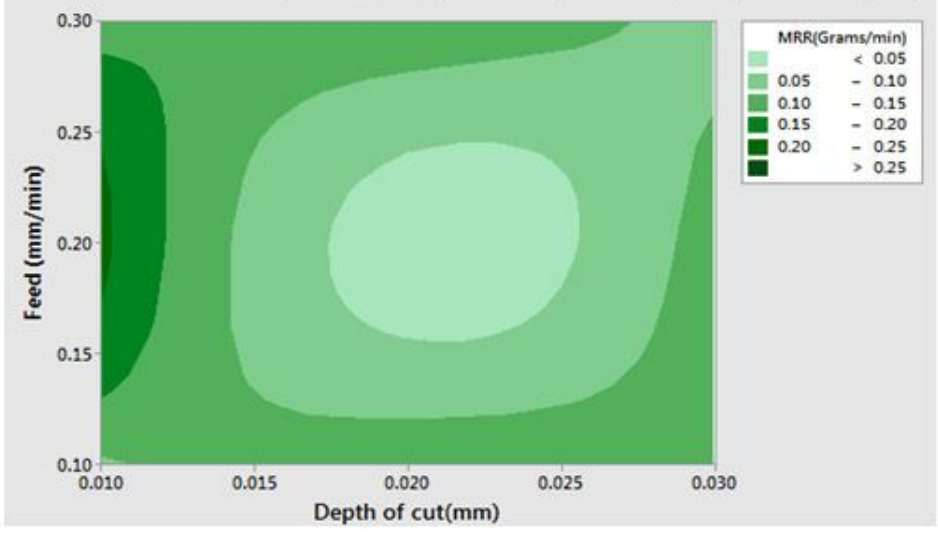

\section{Figure 11}

Three dimensional contour plots depicted the primary variables influencing surface roughness for $3 \%$ nano Al2O3 grinding wheel and third less affected variable is kept at middle level. (i. Cutting speed and feed; ii. Cutting speed and Depth of cut; iii. Feed and Depth of cut)

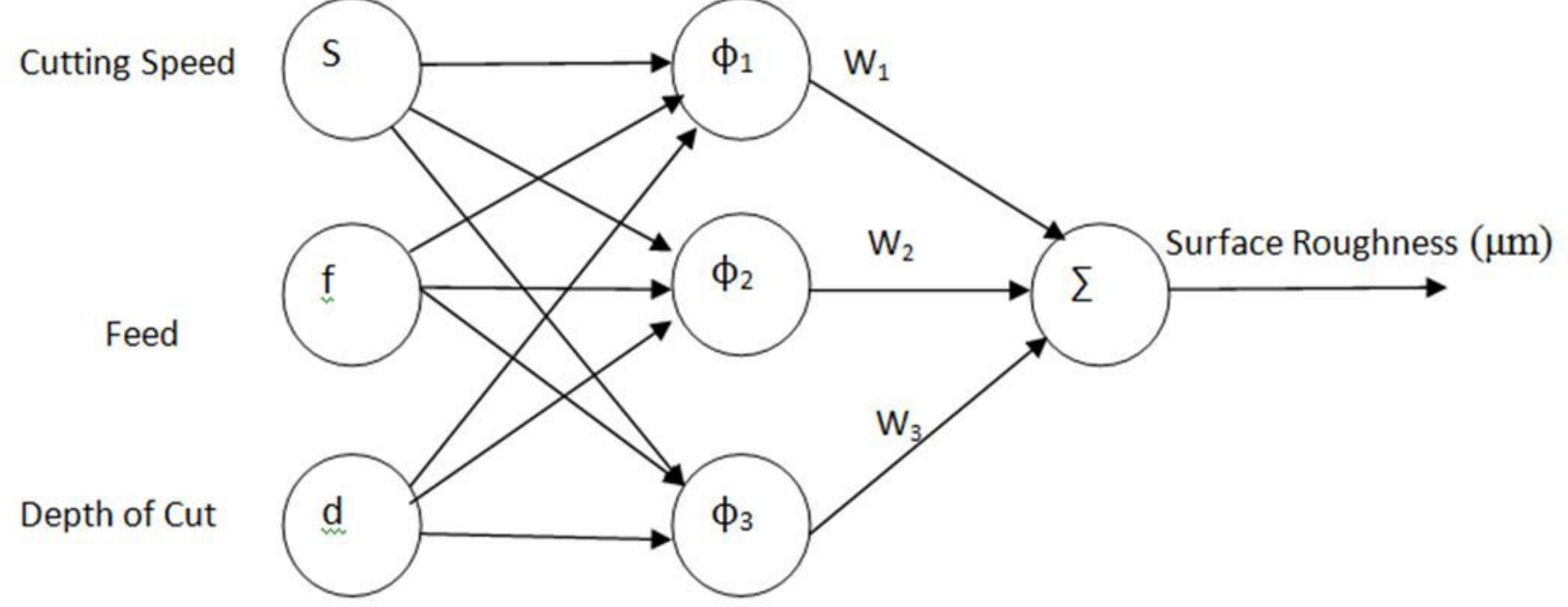


Figure 12

Neural network architecture for nano grinding wheel machining
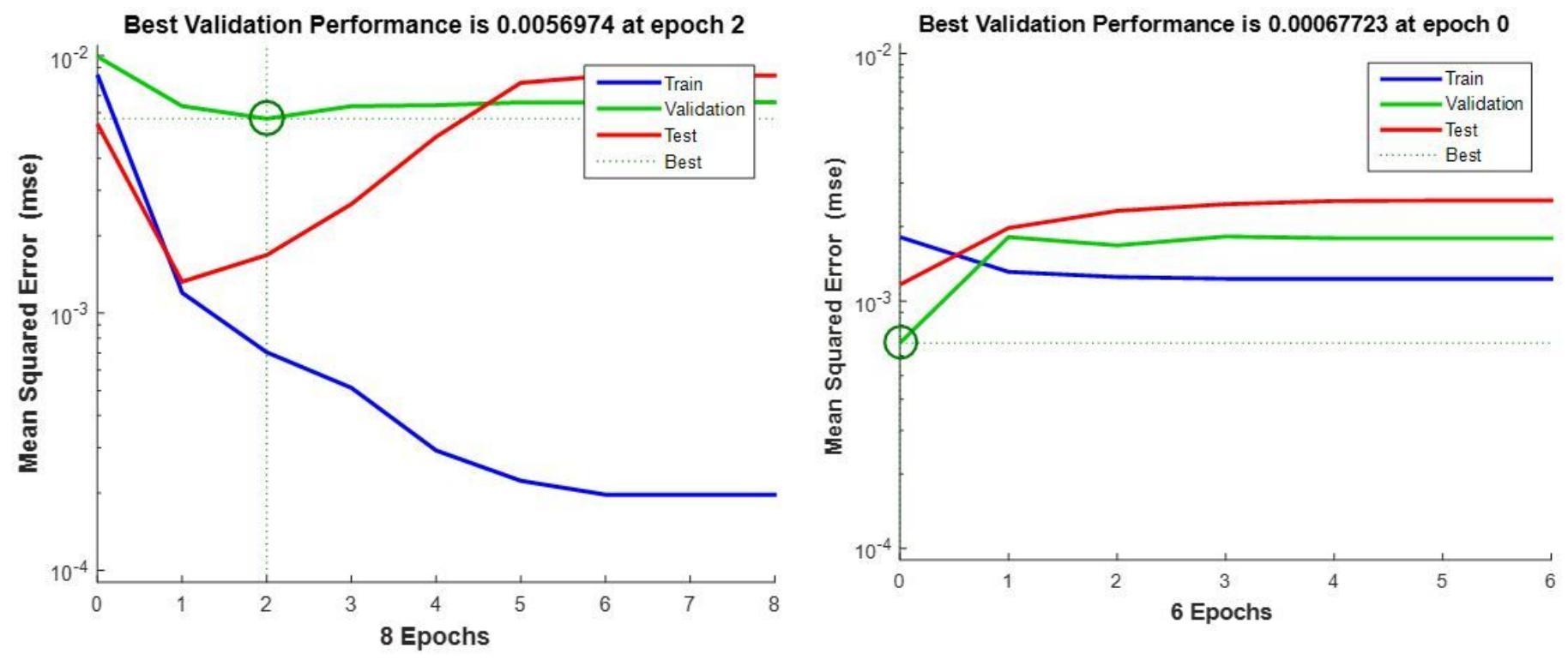

Figure 13

Mean square error for Normal grinding wheel (left) and Nano grinding wheel (Right)
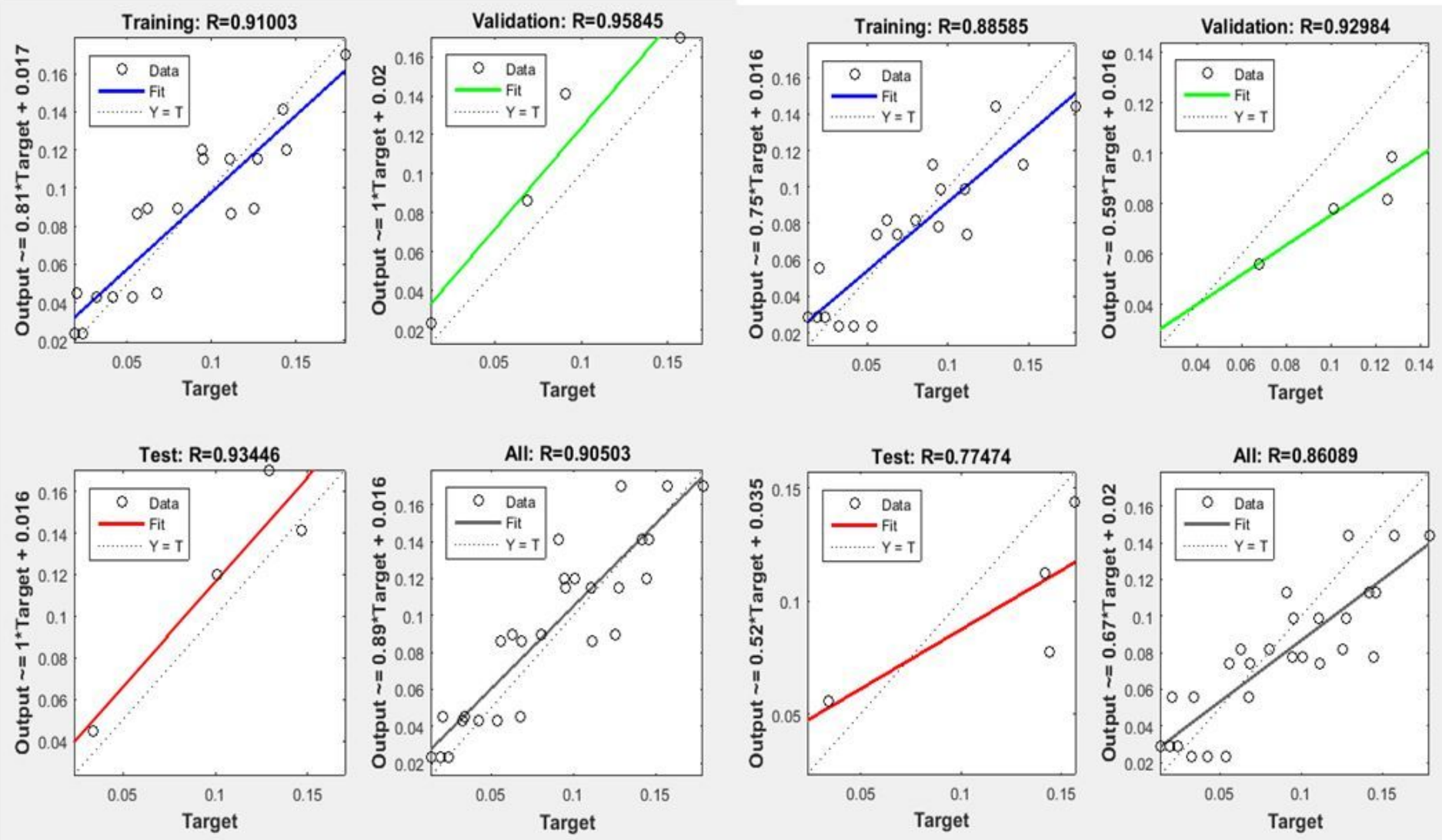


\section{Figure 14}

Liner regression plot with Neural network model and target data for output surface roughness
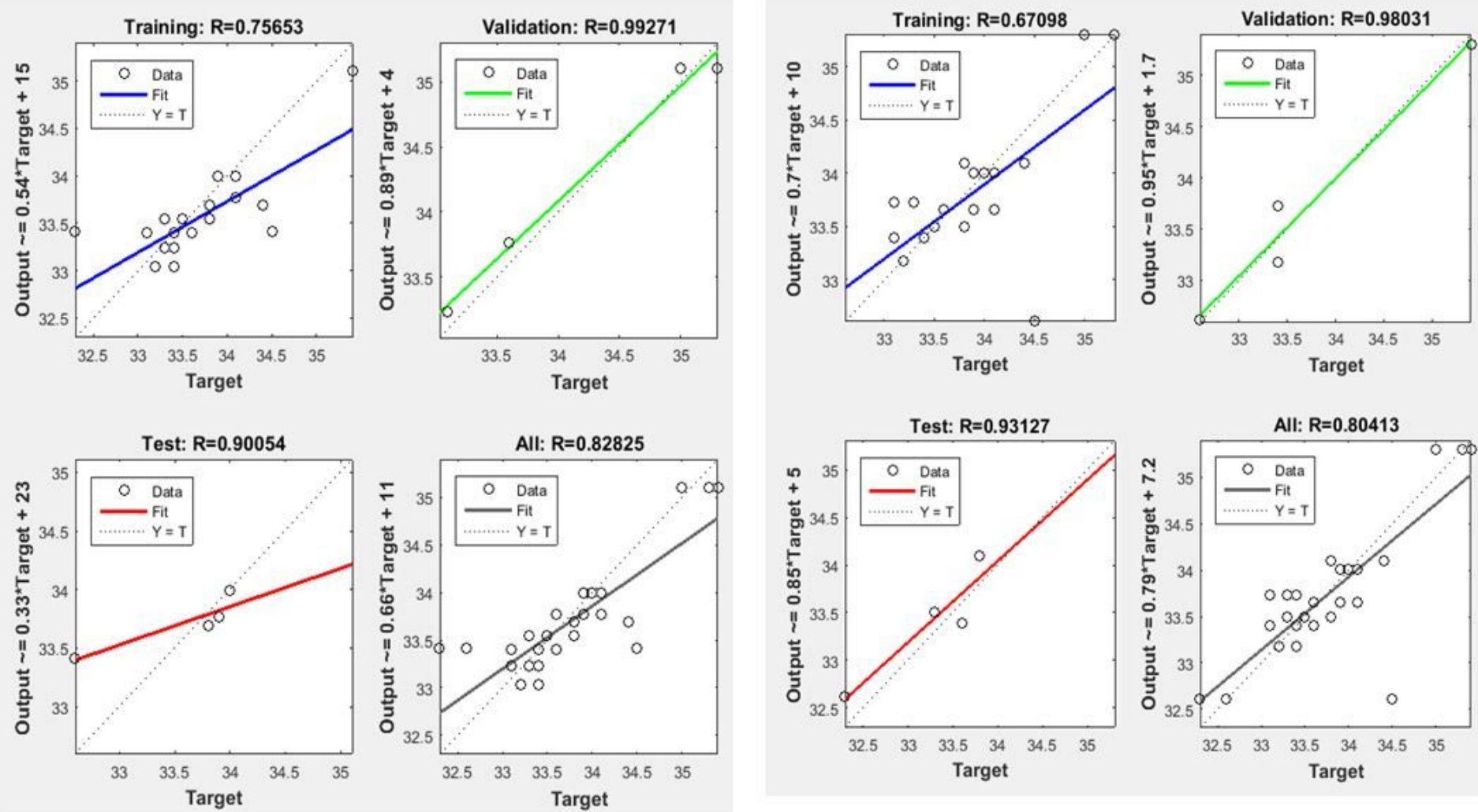

\section{Figure 15}

Temperature responses of 3\% Al203 nano grinding wheel (left) and Ordinary Grinding wheel (Right)

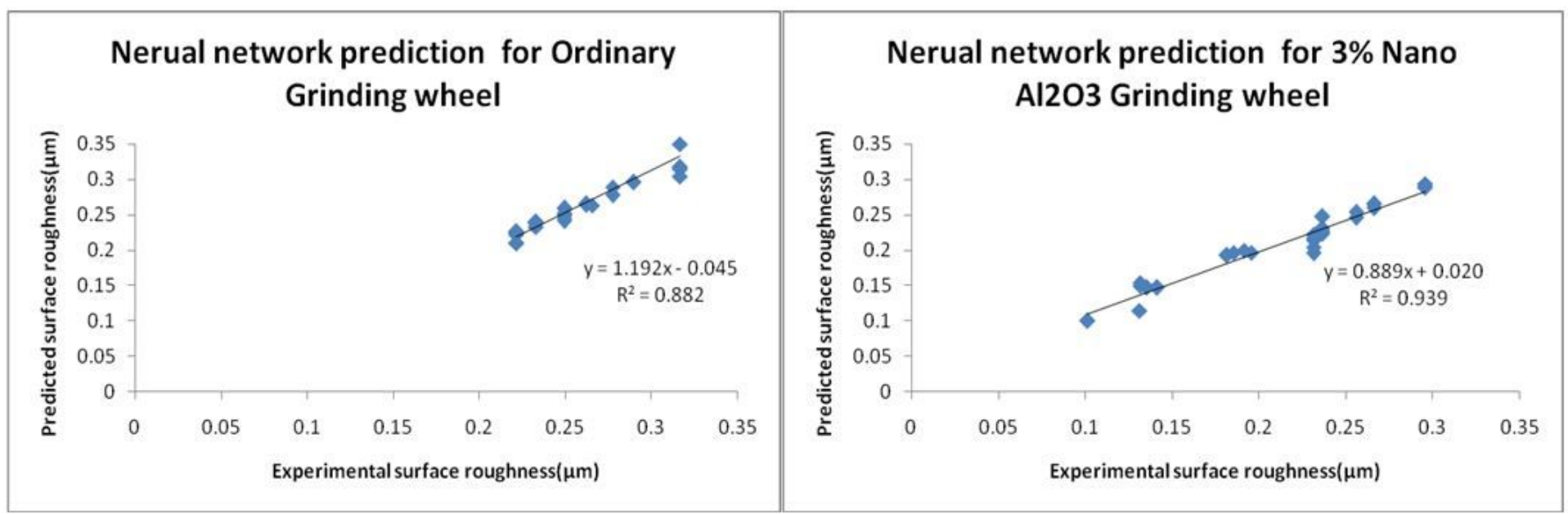

\section{Figure 16}

Neural network surface roughness prediction model for grinding wheels with and without 3\% Al2O3 nano powder 


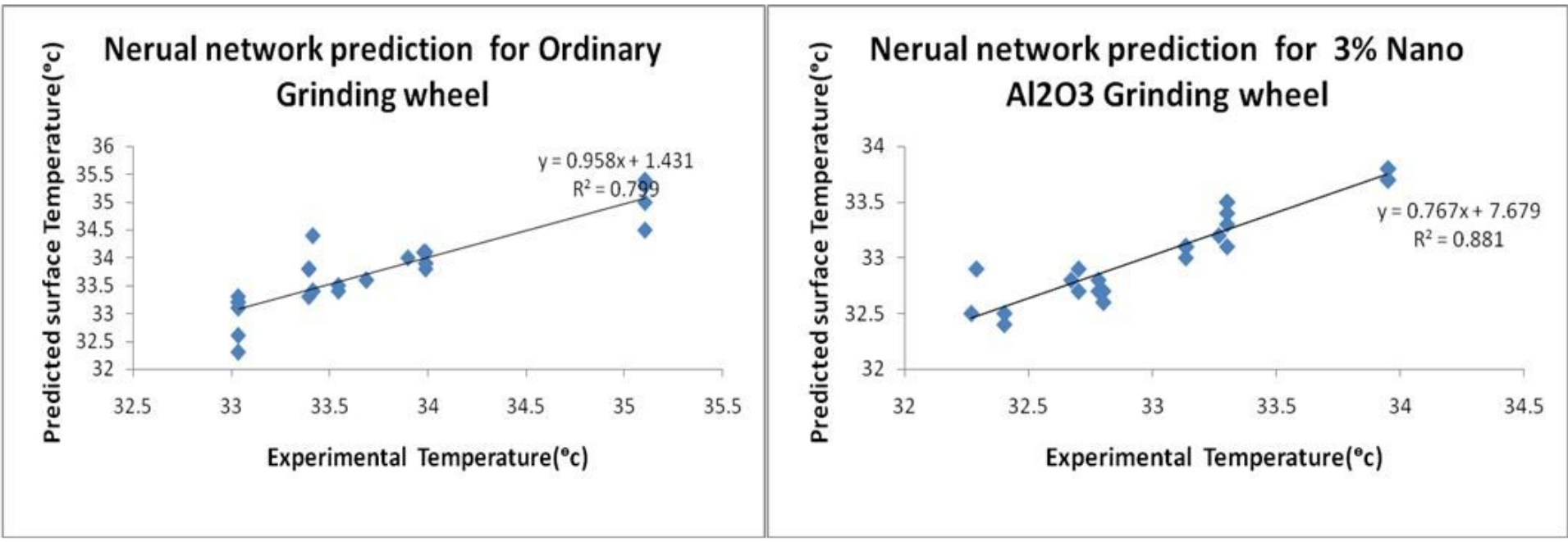

Figure 17

Neural network surface temperature prediction model for ordinary grinding wheel and 3\% Al2O3 nano grinding wheel 